\title{
Artículos
}

\section{Análisis de coyuntura económica ${ }^{1}$}

\author{
Segundo semestre de 1998
}

Departamento de Economía

Universidad Centroamericana "José Simeón Cañas"

\section{Resumen}

Este artículo corresponde al segundo análisis semestral sobre la producción y el empleo, los precios y salarios reales, la racionalidad de dolarizar la economía, y sobre los sectores financiero, público y externo. Aquí se destaca que el ritmo del crecimiento económico se debilita por el escaso poder de compra de los salarios, el raquítico crecimiento del consumo privado, las elevadas tasas de interés, el deterioro de la competitividad real y la delincuencia. El modelo económico vigente ha generado una trayectoria de crecimiento con subempleo y desigualdad. De allí que el valor de estos análisis coyunturales reside en sus implicaciones para descubrir y constatar problemas o debilidades de tipo estructural de la economía salvadoreña. ¿Será que el modelo económico vigente ha entrado a una fase de agotamiento?

1. Documento elaborado por Mario Montesino (secciones 1 y 2), Alvaro Trigueros (secciones 3, 4, 5 y 7), Francisco Lazo Marín (sección 6) y Rafael Pleitez (introducción y conclusiones). También se agradecen las sugerencias y discusiones de Francisco Javier Ibisate S.J., Aquiles Montoya y Gerardo Olano. 


\section{Introducción}

En 1998, el Departamento de Economía inició los análisis de coyuntura económica semestrales. Un aspecto importante que se deriva de estos análisis es que en los movimientos coyunturales de los agregados económicos se evidencian problemas estructurales de la economía salvadoreña. Desde esta perspectiva, el crecimiento económico se ha debilitado a partir del escaso poder de compra de los salarios, el raquítico crecimiento del consumo privado y las elevadas tasas de interés. Junto a estos factores también ha incidido el deterioro de la competitividad real de las empresas y el clima de delincuencia. En el sector público se destaca el problema crónico de la evasión fiscal, como determinante de la baja carga tributaria y el creciente déficit fiscal. Por el lado del sector externo se subraya que las actuales condiciones macroeconómicas no serían sostenibles sin el flujo de remesas familiares.

El presente informe se ha dividido en apartados que analizan: la producción y el empleo, los precios y salarios reales, la racionalidad de dolarizar la economía, y los sectores financiero, público y externo. Además, se estima el impacto económico causado por los efectos del huracán "Mitch".

En cuanto a la producción, el crecimiento económico proyectado por el Banco Central del 4.5 por ciento no se alcanzó, entre otros factores por el impacto económico de "Mitch". Las nuevas estimaciones preliminares de crecimiento están entre el 3 y 3.5 por ciento, respectivamente. Los sectores más dinámicos fueron la manufactura y la construcción; mientras que el comercio se mantuvo estancado. En términos de generación de empleo formal sobresalen la manufactura, el transporte y el sector financiero. Las pérdidas ocasionadas por "Mitch" se han estimado en más del 1.2 por ciento del Producto Interno Bruto, entre las cuales el sector agrícola fue el más afectado.

En relación con los precios, si bien la inflación de 1998 registró un repunte con respecto a 1997, 4.2 por ciento en comparación con el 1.9 por ciento, el país mantiene una de las tasas más bajas de América Latina. La especulación generada por los efectos económicos de "Mitch" y los incrementos de las tarifas eléctricas se señalan como los principales factores que impulsaron la inflación.

En cuanto a los salarios reales, el salario mínimo registra un incremento de 4.6 por ciento, entre diciembre de 1997 y 1998. Sin embargo, los trabajadores no percibieron un aumento significativo en su capacidad adquisitiva debido al incremento en la cotización para el fondo de pensiones. Cabe destacar que el poder de compra del salario mínimo en diciembre de 1998 todavía fue menor que en 1989. La evolución del salario promedio real, a partir de los salarios registrados en el Instituto Salvadoreño del Seguro Social y las AFP, muestra un estancamiento en 1998. Asimismo, a pesar de haber seguido una tendencia creciente en el período 1992-1997, aún se encuentra por debajo del nivel correspondiente a diciembre de 1989.

En el sector financiero, los indicadores del sector bancario en su conjunto presentan una tendencia a disminuir el grado de sanidad del sistema. Por ejemplo, entre marzo de 1997 y septiembre de 1998 , se observa un leve incremento en la morosidad y los créditos de alto riesgo. Una vez más, la crisis del banco Credisa ha evidenciado las debilidades de la supervisión bancaria en el país. Por tanto, es urgente reforzar el marco institucional de regulación y supervisión del sistema financiero.

Las tasas de interés nominales, activas y pasivas, han mostrado una tendencia a la baja, desde diciembre de 1996. La tasa de interés real activa dio un salto considerable en 1997, la cual se mantuvo por arriba del 10 por ciento a lo largo de 1998.

En el sector público se pone de manifiesto el crónico problema de la evasión fiscal que incide en mantener una baja carga tributaria. Un dato que refleja la magnitud del problema de la evasión, es que sólo 4,118 personas naturales declararon una renta imponible mayor a 200,000 colones al año en 1997. El Ministerio de Hacienda presentó el presupuesto de 1999 a la Asamblea Legislativa con un déficit de 2,189 millones, y todavía no ha sido aprobado.

Con respecto al sector externo, las exportaciones mostraron una raquítica tasa de crecimiento de 1.2 por ciento, debido a la caída en la producción y los precios del café. Excluyendo al café, las exportaciones crecieron a una tasa del 11.9 por ciento. Cabe destacar que la maquila por primera vez superó al café en exportaciones netas. El déficit de la balanza comercial fue de 1,513 millones de dólares, esto es, 190 millones de dólares más alto que en 1997. Las remesas ascendieron a 1,332 millones de dólares y se reafirman como la tabla de 
salvación del déficit externo. La balanza de capitales y pagos arrojaron saldos positivos de 386 y 303 millones de dólares, respectivamente.

Recientemente ha resurgido la idea de dolarizar la economía. Para adoptar ese esquema, un país debe cumplir con ciertos requisitos, como un sistema financiero sano y supervisado en forma efectiva. Además, la dolarización puede generar posibles beneficios como la reducción en las tasas de interés, pero también desventajas, como los costos del proceso de ajuste ante una perturbación externa, en términos de mayor desempleo o reducción en los salarios. En consecuencia, es importante evaluar en forma responsable los posibles impactos positivos y negativos de esta medida, y asegurarse del cumplimiento de los requisitos mínimos.

\section{Evolución de la producción y el empleo}

Con respecto al Producto Interno Bruto, para 1998 se pronosticaba una tasa de crecimiento comprendida entre el 4 y 5 por ciento. En efecto, los datos recabados hasta octubre sobre el comportamiento del IVAE confirmaban ese pronóstico. Sin embargo, las pérdidas ocasionadas por la tormenta tropical Mitch al aparato productivo -en especial en el sector agropecuario-, han llevado a estimar una tasa de crecimiento del PIB entre el 3 y 3.5 por ciento, respectivamente.

\subsection{Actividad económica}

Los ritmos de crecimiento del promedio móvil del IVAE, desde enero de 1995 hasta octubre de 1998, se presentan en la Gráfica 1.

\section{Gráfica 1}

IVAE: Promerio móvil 12 meses (variaciones anuales)

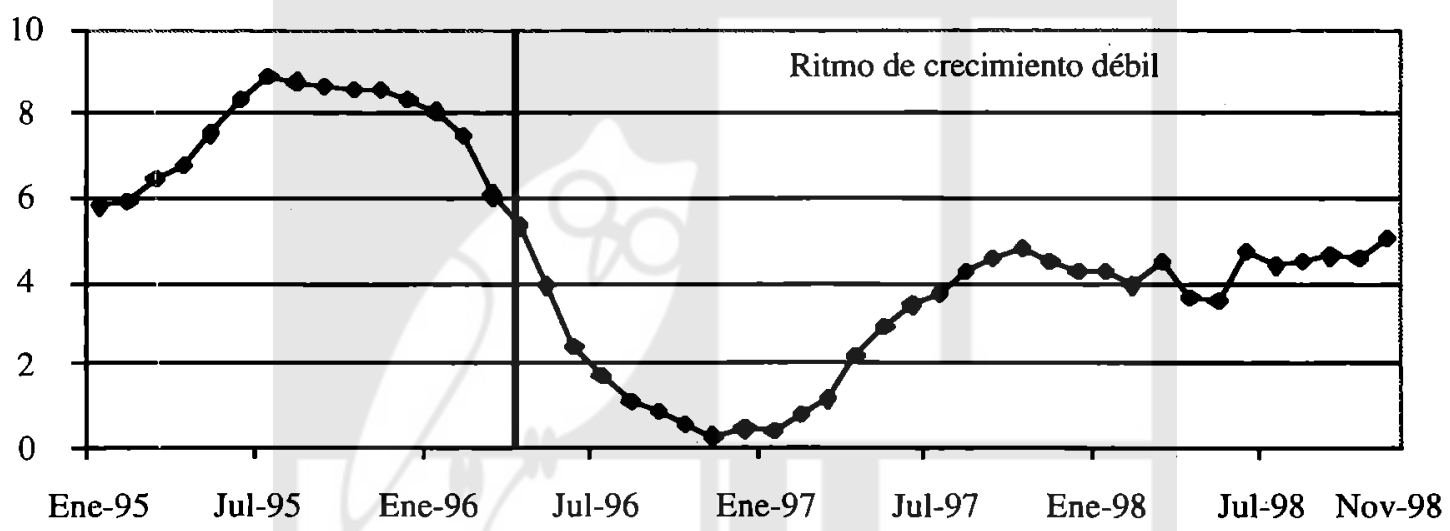

Fuente: Banco Central de Reserva.

En el segundo semestre de 1998, el IVAE mostró un comportamiento consistente con la trayectoria de crecimiento del primer semestre. Esta tendencia ha sido impulsada en especial por el dinamismo de sectores como el agropecuario (hasta octubre), la manufactura y la construcción. No obstante, es necesario destacar que los ritmos de crecimiento en estos sectores han ido aumentando con relativa lentitud, lo cual se refleja en los leves cambios que se observan en la tasa de crecimiento del IVAE desde 1996. A esto viene a sumarse el hecho de que sectores como el comercio, la elec- tricidad y el transporte presentan en este segundo semestre una reducción en sus ritmos de crecimiento. En particular, el sector comercio ha sido el más afectado durante 1998, y ha presentado tasas de crecimiento negativas en su promedio móvil (ver Gráfica 2).

Entre finales de octubre y la primera mitad de noviembre, el país se vio azotado por las secuelas del huracán Mitch. El impacto de este fenómeno se concentró principalmente en las áreas rurales con un saldo en pérdidas de vidas humanas de 240 muertos y más de 80,000 damnificados ${ }^{2}$. Además,

2. Datos del Comité de Emergencia Nacional. 


\section{Gráfica 2 \\ IVAE del comercio: promedio móvil 12 meses \\ (Variaciones anuales)}

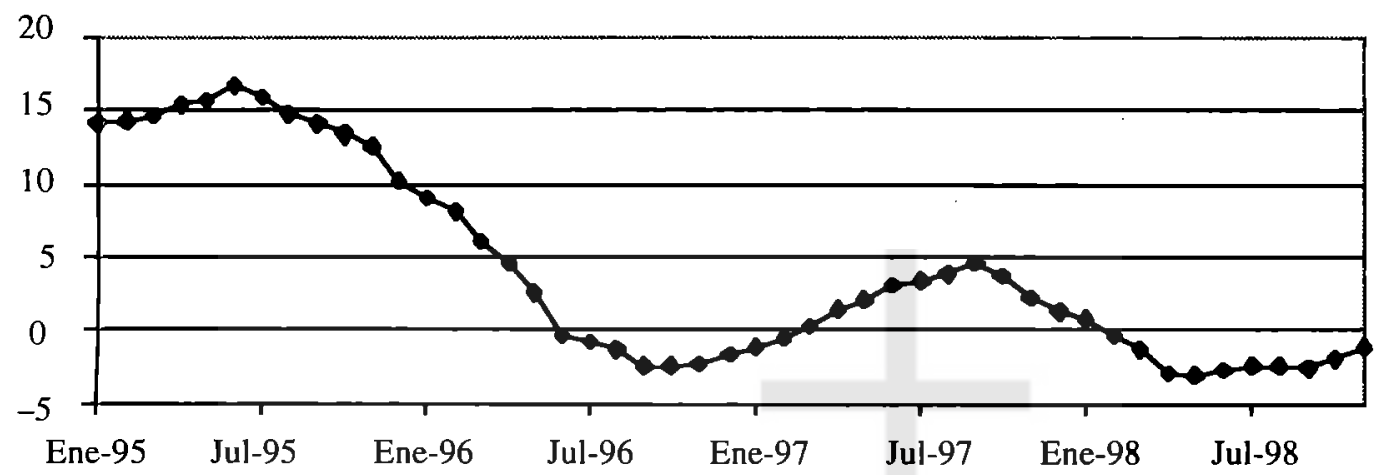

Fuente: Banco Central de Reserva de El Salvador.

generó millonarias pérdidas en la producción del sector agropecuario, que incidieron de manera negativa en la actividad económica de todo el país. El efecto concreto de las pérdidas en volúmenes de producción y pecuniarias se detallarán en el apartado que sigue.

Por otro lado, la serie del IVAE evidencia que la economía nacional se encuentra lejos de alcanzar los ritmos de crecimiento obtenidos entre 1992 y 1995. Es decir, todavía no se advierten señales de una recuperación y menos aún de un crecimiento vigoroso. Ante tal escenario, parece muy difícil que el país inicie el rumbo del desarrollo y mejoramiento de la calidad de vida de la población. Este deficiente desempeño de la economía en el plano coyuntural se explica en el plano estructural a partir del patrón de crecimiento adoptado. El sector agropecuario continúa en abandono, en detrimento de la economía nacional, dado que es uno de los tres sectores más importantes en la generación de empleo y producción. Sin la reactivación de este sector, difícilmente se podrán mejorar las condiciones de vida de la población rural y potenciar la actividad económica en general.

En la actualidad, el estímulo al crecimiento se torna más difícil con respecto a la primera mitad de la década, cuando se reactivó la demanda y la producción interna a raíz de los acuerdos de paz. Desde esa perspectiva se identifican algunas con- diciones que inhiben el crecimiento de la economía: el escaso poder de compra de los salarios, el raquítico crecimiento del consumo privado, las elevadas tasas de interés, el deterioro de la competitividad real y la delincuencia. Para lograr un crecimiento mayor y más sostenido, reiteramos la importancia de la inversión en infraestructura y recursos humanos, así como el fortalecimiento del marco institucional que garantiza el ejercicio de la ley y el derecho.

En torno a la evolución de la demanda agregada, en 1996 y 1997 el consumo privado creció a 1.0 y 1.5 por ciento, respectivamente; mientras que en términos per cápita — consumo por persona- se redujo en 1.0 y 0.6 por ciento, respectivamente. De 1998 no se dispone de información sobre consumo privado, pero considerando el menor crecimiento de la economía en relación con 1997 , no es de esperarse una fuerte recuperación del consumo privado. Por supuesto, la demanda agregada incluye otros componentes, como la inversión (cuya contribución al crecimiento fue aún menor que el del consumo privado en 1996 y 1997) y las exportaciones, pero el principal componente es el consumo privado.

Otro factor que ha repercutido en los bajos niveles de inversión $\mathrm{y}$, por tanto, en el crecimiento económico, es la combinación de las políticas monetaria y fiscal que se ha implementado en los úl- 
timos tres años. De por sí, la política monetaria y cambiaria tienen por objetivo mantener tasas de inflación bajas y la estabilidad en el colón. Pero el enorme flujo de divisas provenientes de remesas familiares obliga al Banco Central a comprar dólares para mantener la estabilidad cambiaria, y con ello se ejerce una presión sobre la tasa de interés y se mantienen altas. Esta presión es reforzada por el financiamiento interno y externo de los recientes déficits fiscales. Es necesario que la política económica conduzca a un alivio de la presión sobre las tasas de interés, y la vía más adecuada sería una mayor disciplina en las finanzas públicas.

\subsection{Empleo}

Al analizar el comportamiento del empleo a través de los trabajadores cotizantes del Instituto Salvadoreño del Seguro Social, se observa a través del promedio móvil que la tendencia del empleo formal es a incrementarse. En general, todos los meses de 1998 presentan tasas de crecimiento superior a las del año anterior. En el caso del promedio móvil, los ritmos de aumento del empleo en 1997 fueron negativos, y mostraron aún los efectos de la desaceleración que la economía venía experimentando (ver Gráfica 3).

Es necesario advertir importantes limitaciones en este indicador. En primer lugar, básicamente da cobertura sólo al sector formal urbano (excluyendo el sector público). De donde no se puede usar para evaluar el comportamiento del empleo en el área rural, por lo que sólo es un indicador parcial de la evolución del empleo, pero es el único disponible para el análisis a corto plazo; además, no proporciona información sobre el subempleo y el desempleo. De este modo, el comportamiento de este indicador sólo permite una idea aproximada de la situación del empleo y, por tanto, debe utilizarse con esa reserva.

\section{Gráfica 3}

Trabajadores cotizantes al ISSS

(Total de trabajadores por riesgo común)

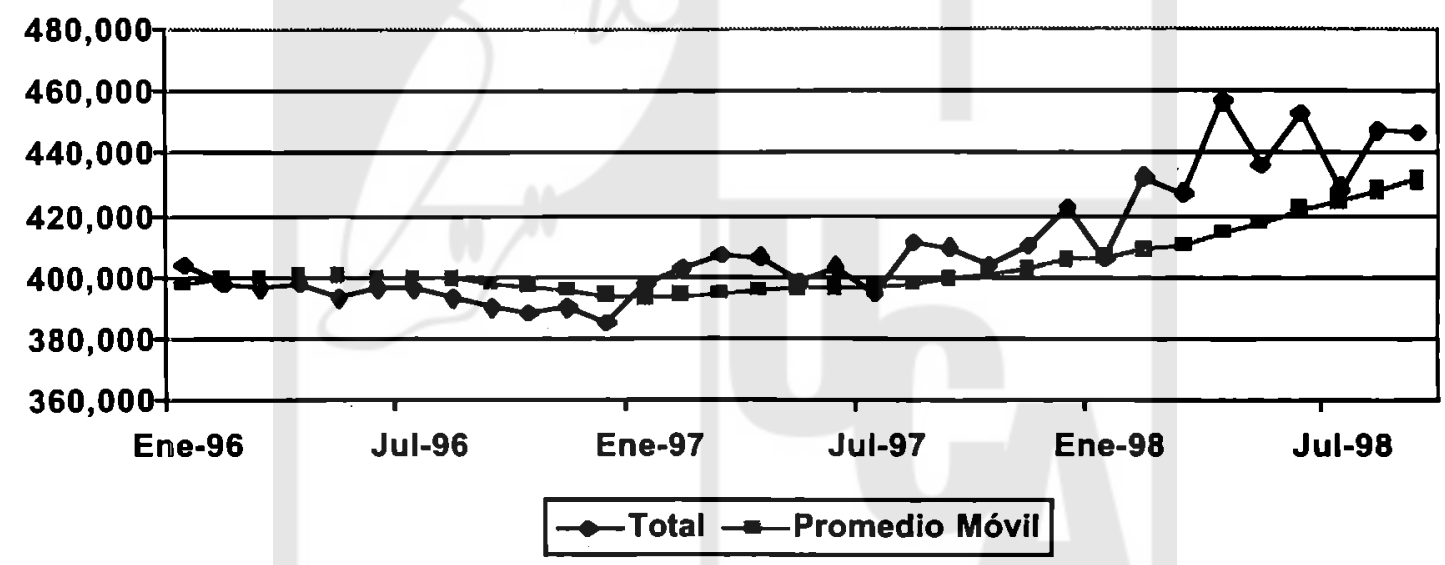

Fuente: Instituto Salvadoreño del Seguro Social.

En el Cuadro 1 se muestra la variación total y el promedio móvil por año $\mathrm{y}$, además, el comportamiento del empleo según la variación mensual. Este último acusa la existencia de caídas temporales del empleo en los meses de mayo, julio y septiembre. Las reducciones estacionales en la dinámica del em- pleo evidenciada en el índice general de los cotizantes al Instituto Salvadoreño del Seguro Social, puede observarse para los mismos meses en el comportamiento de casi todos los sectores económicos, pero cōn mayor relevancia para la construcción, el comercio y el sector financiero (ver Cuadro 2). 


\section{Cuadro 1}

Trabajadores cotizantes del ISSS

por riesgo común

\begin{tabular}{|c|c|c|c|c|c|c|c|c|}
\hline \multirow[b]{3}{*}{ Meses } & \multirow{2}{*}{\multicolumn{2}{|c|}{ Total empleados }} & \multirow{2}{*}{\multicolumn{2}{|c|}{ Variación mensual }} & \multicolumn{4}{|c|}{ Variación anual } \\
\hline & & & & & \multicolumn{2}{|c|}{ Total } & \multirow{2}{*}{$\begin{array}{l}\text { Promedio } \\
1997 \\
\end{array}$} & \multirow{2}{*}{$\begin{array}{r}\text { móvil } \\
1998 \\
\end{array}$} \\
\hline & 1997 & 1998 & 1997 & 1998 & 1997 & 1998 & & \\
\hline ENE & 398,281 & 406,320 & 1.086 & -3.985 & -1.55 & 2.02 & -1.12 & 3.33 \\
\hline FEB & 402,936 & 431,845 & 1.169 & 6.282 & 1.32 & 7.17 & -1.35 & 3.83 \\
\hline MAR & 407,089 & 426,910 & 1.031 & -1.143 & 2.78 & 4.87 & -1.16 & 4.01 \\
\hline $\mathrm{ABR}$ & 406,729 & 456,517 & -0.088 & 6.935 & 2.19 & 12.24 & -1.16 & 4.87 \\
\hline MAY & 398,333 & 435,753 & -2.064 & -4.548 & 1.27 & 9.39 & -0.99 & 5.54 \\
\hline JUN & 403,121 & 451,976 & 1.202 & 3.723 & 1.69 & 12.12 & -0.78 & 6.42 \\
\hline JUL & 395,077 & 428,992 & -1.995 & -5.085 & -0.24 & 8.58 & -0.72 & 7.16 \\
\hline $\mathrm{AGO}$ & 411,671 & 447,198 & 4.200 & 4.244 & 4.77 & 8.63 & -0.41 & 7.48 \\
\hline SEP & 409,862 & 446,304 & -0.439 & -0.200 & 5.10 & 8.89 & 0.46 & 7.79 \\
\hline OCT & 404,124 & & -1.400 & & 4.13 & & 1.08 & \\
\hline NOV & 410,733 & & 1.635 & & 5.32 & & 1.80 & \\
\hline DIC & 423,185 & & 3.032 & & 9.94 & & 3.03 & \\
\hline
\end{tabular}

Fuente: Instituto Salvadoreño del Seguro Social.

\section{Cuadro 2}

Trabajadores cotizantes del ISSS

por riesgo común: principales ramas por empleo formal

(variación mensual)

\begin{tabular}{|c|c|c|c|c|c|c|c|c|c|c|}
\hline \multirow[b]{2}{*}{ Meses } & \multicolumn{2}{|c|}{ Manufactura } & \multicolumn{2}{|c|}{ Construcción* } & \multicolumn{2}{|c|}{ Comercio } & \multicolumn{2}{|c|}{ Financiero } & \multicolumn{2}{|c|}{ Serv. Perso. } \\
\hline & 1997 & 1998 & 1997 & 1998 & 1997 & 1998 & 1997 & 1998 & 1997 & 1998 \\
\hline ENE & 5.61 & -2.07 & 2.61 & -2.79 & 2.69 & -5.38 & 0.18 & -1.62 & 1.12 & -7.47 \\
\hline FEB & 0.77 & 6.90 & 5.75 & -6.39 & -0.98 & 7.17 & 0.97 & 2.43 & 5.56 & 5.47 \\
\hline MAR & -0.86 & -2.10 & 1.36 & 5.27 & -0.99 & -4.40 & 0.89 & 1.85 & 5.90 & 0.34 \\
\hline ABR & 0.36 & 4.59 & 3.74 & 15.20 & -1.16 & 6.45 & 1.46 & 7.89 & -2.32 & 5.68 \\
\hline MAY & -2.07 & -4.17 & 0.31 & -12.90 & -1.82 & -3.96 & -1.31 & -2.55 & -2.79 & 0.47 \\
\hline JUN & 1.03 & 2.08 & 6.65 & 12.93 & -0.74 & 2.18 & 0.55 & 3.63 & 1.64 & 5.00 \\
\hline JUL & 1.21 & -4.59 & -9.24 & -11.83 & 0.66 & -2.02 & -5.79 & -8.11 & -1.67 & -3.77 \\
\hline AGO & 2.00 & 2.33 & 2.41 & 7.92 & 3.14 & 1.29 & 7.75 & 9.25 & 5.13 & 5.84 \\
\hline SEP & -0.87 & 0.17 & -1.36 & -2.26 & 1.11 & -2.23 & -2.67 & -0.36 & 0.70 & 2.71 \\
\hline OCT & -2.95 & & 2.03 & & -0.90 & & 2.40 & & -1.90 & \\
\hline NOV & 3.67 & & -5.34 & & 0.64 & & 4.04 & & -0.51 & \\
\hline DIC & 3.60 & & 2.84 & & 3.83 & & 0.46 & & 1.83 & \\
\hline
\end{tabular}

Fuente: Instituto Salvadoreño del Seguro Social.

*Pública y privada. 
Los sectores que registran una notable incidencia en la generación de empleo son la industria manufacturera, el sector financiero y el de transporte. La creación de empleo en el comercio mostró una tendencia mejor que la del año anterior en el primer semestre, pero de julio a septiembre su comportamiento fue menos dinámico que en 1997.

\section{Efectos del huracán Mitch en la agricultura}

Como se mencionó en la sección anterior, en 1998 la agricultura mostraba señales de recuperación, pero en el segundo semestre, el país fue azotado por una tormenta tropical que afectó a casi todo el istmo centroamericano. En términos económicos, los efectos de este fenómeno meteorológico se experimentaron principalmente en el sector agropecuario, especialmente en la producción de granos básicos, café, caña y pezca. En los apartados que siguen se resume el impacto del fenómeno del Mitch en relación con estos subsectores.

\subsection{Subsector de granos básicos}

La superficie sembrada de granos básicos que fue dañada por las inundaciones asciende a 92,765 manzanas. El 39 por ciento estaban ubicadas en el departamento de Usulután, el 14.5 por ciento en San Vicente y el 12.2 por ciento en el departamento de Santa Ana. El rubro principalmente dañado por las inundaciones ha sido el maíz con un 67 por ciento aproximadamente, seguido del frijol con un

Cuadro 3

Efectos del huracán Mitch en los cultivos de granos básicos

\begin{tabular}{lcccc}
\hline Cultivo & $\begin{array}{c}\text { Rendimiento normal } \\
\text { esperado (qq/Mz.) }\end{array}$ & $\begin{array}{c}\text { Rendimiento esperado } \\
\text { por daño (qq/Mz.) }\end{array}$ & $\begin{array}{c}\text { Producción esperada } \\
\text { millones de (qq.) }\end{array}$ & $\begin{array}{c}\text { Pérdida } \\
\text { millones (qq.) }\end{array}$ \\
\hline Maíz & 35.4 & 31.8 & 11.4 & 1.3 \\
Sorgo & 25.5 & 24.0 & 3.5 & 0.2 \\
Frijol & 13.5 & 9.5 & 0.6 & 0.3 \\
Arroz & 91.3 & 77.6 & 1.0 & 0.1 \\
Total & & & 16.5 & 1.9 \\
\hline
\end{tabular}

Fuente: MAG, "Acciones para responder al fenómeno Mitch", Oficina de Análisis de Política Agropecuaria.

3. Oficina de Análisis de Política Agropecuaria (OAPA), "Acciones para responder al fenómeno Mitch", Ministerio de Agricultura y Ganadería. 
Es importante observar que, considerando los rendimientos, el rubro más afectado es el cultivo del frijol, para el cual la disminución en los rendimientos ha sido del 30 por ciento; seguido por el arroz, en un 15 por ciento; el maíz, en 10 por ciento, y el sorgo con 6 por ciento. Sin embargo, tomando en cuenta los volúmenes de producción, los rubros más afectados son el maíz y el frijol.

En términos monetarios, las pérdidas sufridas por el subsector de granos básicos fueron de 467.3 millones, de éstas, el 58 por ciento corresponde al cultivo del maíz; además, el porcentaje de pérdida de este rubro con respecto a lo esperado fue del 23.9 por ciento, el más alto de todos los cultivos de granos básicos después del frijol, para el cual este porcentaje es de 38 por ciento más o menos ${ }^{4}$.

\subsection{Subsector pesquero y camaronicultura}

La pesca del camarón se vio drásticamente afectada. Las pérdidas se estiman en 14 millones de colones, correspondientes a una pérdida productiva equivalente a 377 miles de kilogramos. El mayor porcentaje de esta pérdida (58 por ciento en volumen y 82 por ciento en colones) la soportó la pesca tecnificada de camarón y camaroncillo. Por su parte, la camaronicultura experimentó una pérdida en volumen de 170 miles de kilogramos, de los cuales el 40 por ciento los soportó la camaro- nicultura extensiva permanente; esto representó en colones el 38 por ciento de la pérdida en el procesamiento del camarón ${ }^{5}$.

\subsection{Subsector café}

En el caso de la producción de café, los efectos de Mitch vinieron a acumularse a los efectos nocivos del fenómeno del "niño". Las pérdidas en el cultivo de café oro uva, por el fenómeno del niño, se calculan en 250 mil quintales, correspondientes a 137.5 millones de colones. A esto se le agregan 81 mil quintales de pérdidas por el fenómeno del Mitch, que representan 44.5 millones de colones. En total, la pérdida en el subsector asciende a 182 millones, correspondientes a 331,5 miles quintales de café oro uva ${ }^{6}$.

\subsection{Subsector caña de azúcar}

Las pérdidas en el sector cañero representaron, en volumen, el 15 por ciento de una producción esperada de 5.5 millones de toneladas cortas. A su vez, esta merma se tradujo en una pérdida en la producción de azúcar equivalente a 1.53 millones de quintales. El ingreso que se dejó de percibir por tales reducciones en la producción, se estima en unos 60 millones de colones.

En el Cuadro 4 se resume el efecto de Mitch en el sector agropecuario.

\section{Cuadro 4}

Efectos del huracán Mitch en el sector agropecuario (en millones)

\begin{tabular}{lccccc}
\hline Cultivo & $\begin{array}{c}\text { Estimado } \\
\text { preliminar } \\
\text { de producción (qq) }\end{array}$ & $\begin{array}{c}\text { Estimado } \\
\text { actual (qq) }\end{array}$ & $\begin{array}{c}\text { Estimado } \\
\text { de pérdida }\end{array}$ & $\begin{array}{c}\text { \% de pérdida } \\
\text { pérdida }\end{array}$ & $\begin{array}{c}\text { Valor en } \\
\text { colones de la } \\
\text { pérdida }\end{array}$ \\
\hline Maíz & 14.8 & 11.3 & 3.5 & 23.9 & 271.0 \\
Sorgo & 4.0 & 3.5 & 0.5 & 11.7 & 28.2 \\
Frijol & 1.5 & 0.9 & 0.5 & 38.1 & 150.3 \\
Arroz & 1.3 & 1.0 & 0.3 & 21.0 & 17.8 \\
\hline Subtotal granos básicos & 21.6 & 16.7 & 4.8 & 22.5 & 467.3 \\
\hline Café (oro uva) & 3.2 & 2.8 & 0.3 & 10.5 & 182.0 \\
Caña (ton. cortas) & 5.5 & 4.7 & 0.8 & 15.0 & 97.0 \\
Pesca (Kg) & & & 0.5 & & 19.8 \\
Total & & & & & 766.1 \\
\hline
\end{tabular}

Fuente: MAG, “Acciones para responder al fenómeno Mitch”, Oficina de Análisis de Política Agropecuaria, 1998.
4. Ibid.
5. Ibid.
6. Ibid. 
En suma, este deterioro en la producción agropecuaria es de considerable importancia para el crecimiento del Producto Interno Bruto. En este caso, si se asume una tasa de crecimiento esperada para 1998 del 4 por ciento (a precios constantes), el impacto de la tormenta tropical sobre el sector agropecuario reduciría ese crecimiento a una tasa de 3.2 por ciento aproximadamente. Ello se debe a que dicha pérdida representa 0.71 por ciento del Producto Interno Bruto corriente esperado y constituye el 5.5 por ciento del Producto Inter-

no Bruto agropecuario corriente, asumiendo que su tasa de variación se mantuviera en el nivel de 1997 ( 8.2 por ciento). Esta situación tiene que provocar un efecto negativo en el nivel de comportamiento del IVAE, el cual lógicamente no alcanzará los niveles esperados que se mencionaron en el informe de coyuntura del primer semestre?

\subsection{Daños ocasionados por Mitch a la infraes- tructura $^{8}$}

Por supuesto, la tormenta tropical Mitch también afectó viviendas, escuelas, vías terrestres, unidades de salud y puentes. El número de escuelas afectadas fue de 818 , que representa más o menos el 17 por ciento del total de las escuelas públicas del país. Casi un 40 por ciento de estas escuelas están definitivamente dañadas, un 28 por ciento se encuentran en alto riesgo y un 32 por ciento ha quedado inaccesible. La mayor parte se ubica en los departamentos de San Vicente, Usulután, San Miguel y La Unión.

El número de viviendas dañadas fue de 10,372, de las cuales el 54 por ciento aproximadamente se encuentra en San Vicente y la zona oriental. Las unidades de salud afectadas por daños en infraestructura ascienden a $15 ; 5$ en Usulután, 4 en Ahuachapán y 1 en San Miguel.

En relación con las vías terrestres, se informan 13,008 kilómetros dañados en carreteras pavimen- tada y 2,665 en no pavimentadas; 10 puentes fueron afectados por las fuertes crecientes de los ríos. Entre estos últimos, dos puentes tipo Bayley colapsaron: el de San Carlos Lempa (Cuscatlán), en San Vicente, y el de San Nicolás Lempa (de oro), en Usulután.

Los daños en las vías terrestres e infraestructura productiva -estimados en más de 500 millones de colones - van a generar más pérdidas al entorpecer la actividad productiva, como es el caso de la destrucción de carreteras y los lugares de almacenamiento de granos.

\section{Evolución de los precios}

\subsection{Nivel general de precios}

Hasta diciembre de 1998, la tasa de inflación anual alcanzó un 4.2 por ciento, permaneciendo dentro de los límites establecidos como metas en el Programa Monetario 1998 del Banco Central de Reserva, que oscilaba entre 2.5 y 4.5 por ciento, respectivamente. Cabe señalar que los niveles de inflación hubieran sido más bajos, de no ser por los efectos negativos que implicó el huracán Mitch. Esto se demuestra con el hecho de que hasta octubre de 1998, la tasa anual de inflación alcanzaba un 1.9 por ciento. Además, en los meses de noviembre y diciembre, los precios de los alimentos tendieron a disminuir con la salida de la cosecha de los granos básicos. En esta ocasión, con la escasez coyuntural por los efectos del huracán Mitch en la agricultura, se informó en noviembre una inflación mensual de 2.2 por ciento, asociada principalmente al alza en los precios de alimentos del 5.4 por ciento. Sin embargo, los precios disminuyeron poco en diciembre. Un punto importante es que el alza en los precios de los alimentos en noviembre no se debió precisamente a los efectos directos del huracán Mitch en la oferta de productos alimenticios - salvo algunas frutas, verduras y vegetales-, ya que el país cuenta con suficientes reservas de granos básicos para satisfacer la demanda a corto plazo. El alza de los precios se debió más que todo a la especulación. Los

7. Departamento de Economía, ECA, 599, septiembre, 1998.

8. La información de esta sección se obtuvo de los datos ofrecidos por el Comité de Emergencia Nacional en diversos medios. 
efectos en los precios - si acaso se harán sentir en los próximos meses- estarán determinados por los niveles bajos de la última cosecha, y por los efectos más fuertes que tuvo Mitch en Honduras, uno de nuestros principales proveedores de productos agrícolas.

Al analizar los diferentes rubros de la canasta que se utiliza para construir el Indice de Precios al Consumidor (IPC), nos encontramos con la limitación de que los datos sólo están disponibles hasta noviembre de 1998. Es de destacar que, este año, los niveles de inflación han sido bastante bajos en todos los rubros, a excepción de los alimentos en noviembre que alcanzó una inflación mensual de 5.4 por ciento. Otro punto por destacar es que los precios de las prendas de vestir y calzado (vestuario) muestran una tendencia a la baja, debido a la apertura del comercio exterior y la reducción de los aranceles de bienes de consumo final, como ha sido la tendencia de los últimos años. Por otra parte, después de los alimentos, la presión inflacionaria más fuerte este año ha provenido del rubro vivienda, principalmente lo que corresponde a electricidad y combustible que, hasta noviembre de 1998, tenían una inflación anual de 14.1 por ciento.

En comparación con otros países, la inflación en El Salvador es de las más bajas del continente. Hasta octubre de 1998, El Salvador tenía la inflación más baja de América Latina, sólo después de Argentina. En el caso de los países centroamericanos, Honduras, Costa Rica y Nicaragua presenta- ban una inflación de dos dígitos hasta noviembre de 1998, y la de Guatemala, aunque de sólo un dígito, fue superior a la de El Salvador (ver Cuadro 5).

\section{Cuadro 5}

Inflación anual en Centroamérica (cifras hasta diciembre de 1998)

\begin{tabular}{lr}
\hline País & Inflación $(\%)$ \\
\hline Costa Rica & 12.35 \\
El Salvador & 4.17 \\
Guatemala & 7.48 \\
Honduras & 15.64 \\
Nicaragua & 18.51 \\
\hline
\end{tabular}

Fuente: Consejo Monetario Centroamericano.

De seguir esta tendencia en los niveles de inflación, se esperaría que 1999 fuera un año positivo en este sentido. Por su parte, la meta de inflación del Banco Central de Reserva en el Programa Monetario y Financiero 1999 oscila entre el 2.5 y 4.5 por ciento, respectivamente, igual que el año anterior. Si el Banco Central de Reserva mantiene la misma combinación de una política monetaria conservadora y un tipo de cambio fijo, se esperaría que esta meta se alcanzara. Otro aspecto por considerar es que los efectos del huracán Mitch no son sólo a corto plazo, también podría afectar la producción agrícola de la región centroamericana, con lo cual habría cierta presión al alza en los precios de los alimentos.

\section{Cuadro 6 \\ Indice de Precios al Consumidor \\ Variación porcentual anual (punto a punto) por grupos \\ Base: diciembre 1992=100}

\begin{tabular}{|c|c|c|c|c|c|c|c|c|c|c|}
\hline \multirow[t]{2}{*}{ Mes } & \multicolumn{2}{|c|}{ General } & \multicolumn{2}{|c|}{ Alimentos } & \multicolumn{2}{|c|}{ Vivienda } & \multicolumn{2}{|c|}{ Vestuario } & \multicolumn{2}{|c|}{ Misceláneos } \\
\hline & 1997 & 1998 & 1997 & 1998 & 1997 & 1998 & 1997 & 1998 & 1997 & 1998 \\
\hline Enero & 7.5 & 1.5 & 11.7 & -0.7 & 5.7 & 5.9 & 1.1 & 0.3 & 4.9 & 1.5 \\
\hline Febrero & 7.8 & 1.3 & 12.1 & -1.1 & 5.9 & 6.1 & 0.7 & -0.1 & 5.3 & 1.1 \\
\hline Marzo & 7.4 & 1.5 & 11.2 & -0.3 & 6.2 & 5.7 & 0.9 & -0.5 & 5.1 & 1.1 \\
\hline Abril & 7.1 & 2.7 & 10.8 & 2.0 & 6.2 & 6.2 & 0.7 & -0.7 & 4.5 & 1.3 \\
\hline Mayo & 6.1 & 3.5 & 8.3 & 3.7 & 5.9 & 6.5 & 0.9 & -0.9 & 4.7 & 1.4 \\
\hline Junio & 4.9 & 3.2 & 5.0 & 3.1 & 6.6 & 6.5 & 0.4 & -0.7 & 5.0 & 1.1 \\
\hline Julio & 4.0 & 2.8 & 3.4 & 1.7 & 6.1 & 6.7 & -0.1 & -0.9 & 4.1 & 2.0 \\
\hline Agosto & 1.8 & 2.2 & -1.0 & 0.7 & 4.9 & 6.3 & -0.1 & -0.9 & 4.4 & 1.8 \\
\hline Septiembre & 2.1 & 1.5 & -0.6 & -0.2 & 6.0 & 5.3 & 0.2 & -0.9 & 3.6 & 1.3 \\
\hline Octubre & 1.7 & 1.9 & -1.0 & 0.7 & 5.5 & 5.5 & 0.0 & -0.9 & 3.4 & 1.2 \\
\hline Noviembre & 2.2 & 4.3 & -0.2 & 7.1 & 6.3 & 4.4 & 0.1 & -0.8 & 3.0 & 1.0 \\
\hline Diciembre & 1.9 & 4.2 & 0.4 & & 4.7 & & 0.0 & & 2.4 & \\
\hline
\end{tabular}

Fuente: Dirección General de Estadística y Censos. 


\subsection{Salarios reales}

El impacto más inmediato de la inflación es el deterioro sobre la capacidad de compra de la población, en especial de los sectores más pobres. Es difícil obtener datos de ingresos para análisis de coyuntura, ya que éstos no se obtienen periódicamente ni de manera oportuna. Bajo tal restricción, sólo se revisará la evolución de los salarios mínimos reales y, con algún tiempo de rezago, la evolución de los salarios promedios con base en las cotizaciones al seguro social y a las AFP.

Dado que el salario mínimo nominal se fija por decreto, y los datos sobre el IPC, y por tanto de la inflación, están disponibles cada mes y en forma oportuna, nos basamos en esta información. En forma adicional se puede comprobar que la gran mayoría de los asalariados reciben el salario mínimo, lo que se pueden comprobar con los datos de Ingreso Base de Cotización (IBC) publicados por la Superintendencia de Pensiones ${ }^{9}$. El IBC modal, al 31 de noviembre de 1998, es de 1,260 colones mensuales, que corresponden al salario mínimo de 42 colones diarios $^{10}$. Además, el IBC mensual promedio hasta noviembre de 1998 era de 2,566.81 colones, poco más del doble del salario mínimo, lo cual refleja los bajos niveles de ingreso de la mayoría de los trabajadores y explica los bajos niveles de demanda.

Cuadro 7

Evolución de los salarios reales

\begin{tabular}{llccccc}
\hline Año & $\begin{array}{c}\text { Salario } \\
\text { mínimo } \\
\text { nominal }\end{array}$ & $\begin{array}{c}\text { Aumento } \\
\text { salarial } \\
\text { nominal }\end{array}$ & $\begin{array}{c}\text { IPC } \\
\text { Base } \\
1992\end{array}$ & $\begin{array}{c}\text { Salario } \\
\text { real } \\
\text { dic/92=100 }\end{array}$ & $\begin{array}{c}\text { Indice del } \\
\text { salario real } \\
\text { dic/88=100 }\end{array}$ & $\begin{array}{c}\text { Cambio } \\
\text { Porcentual }\end{array}$ \\
\hline 1988 & C18.00 & & 51.52 & C 34.94 & 100.0 & \\
1989 & C18.00 & $0.0 \%$ & 63.61 & C28.30 & 81.0 & $-19.0 \%$ \\
1990 & C21.00 & $16.7 \%$ & 75.92 & C27.66 & 79.2 & $-2.3 \%$ \\
1991 & C23.50 & $11.9 \%$ & 83.38 & C28.18 & 80.7 & $1.9 \%$ \\
1992 & C27.00 & $14.9 \%$ & 100.00 & C27.00 & 77.3 & $-4.2 \%$ \\
1993 & C31.00 & $14.8 \%$ & 112.09 & C27.66 & 79.2 & $2.4 \%$ \\
1994 & C35.00 & $12.9 \%$ & 122.06 & C28.67 & 82.1 & $3.7 \%$ \\
1995 & C38.50 & $10.0 \%$ & 135.94 & C28.32 & 81.1 & $-1.2 \%$ \\
1996 & C38.50 & $0.0 \%$ & 145.95 & C26.38 & 75.5 & $-6.9 \%$ \\
1997 & C38.50 & $0.0 \%$ & 148.76 & C25.88 & 74.1 & $-1.9 \%$ \\
Ene-98 & C38.50 & $0.0 \%$ & 150.6 & C25.56 & 73.2 & $-1.2 \%$ \\
Feb-98 & C38.50 & $0.0 \%$ & 150.99 & C25.50 & 73.0 & $-0.3 \%$ \\
Mar-98 & C38.50 & $0.0 \%$ & 151.65 & C25.39 & 72.7 & $-0.4 \%$ \\
Abr-98 & C38.50 & $0.0 \%$ & 153.51 & C25.08 & 71.8 & $-1.2 \%$ \\
May-98 & C42.00 & $9.1 \%$ & 154.32 & C27.22 & 77.9 & $8.5 \%$ \\
Jun-98 & C42.00 & $0.0 \%$ & 154.46 & C27.19 & 77.8 & $-0.1 \%$ \\
Jul-98 & C42.00 & $0.0 \%$ & 155.15 & C27.07 & 77.5 & $-0.4 \%$ \\
Ago-98 & C42.00 & $0.0 \%$ & 153.26 & C27.40 & 78.4 & $1.2 \%$ \\
Sep-98 & C42.00 & $0.0 \%$ & 151.66 & C27.69 & 79.3 & $1.1 \%$ \\
Oct-98 & C42.00 & $0.0 \%$ & 151.76 & C27.68 & 79.2 & $-0.1 \%$ \\
Nov-98 & C42.00 & $0.0 \%$ & 155.12 & C27.08 & 77.5 & $-2.2 \%$ \\
Dic-98 & C42.00 & $0.0 \%$ & 155.03 & C27.09 & 77.5 & $0.1 \%$ \\
\hline
\end{tabular}

Fuente: Para el salario mínimo, la fuente fue el Ministerio de Trabajo, y para el IPC, la Dirección General de Estadística y Censos del Ministerio de Economía.

9. Superintendencia de Pensiones, Boletín Indicadores Previsionales, 6, noviembre, 1998, pp. 10.

10. La moda es la cifra que se repite el mayor número de veces. 
Dos aspectos sobresalen este año en relación con los salarios reales. Primero, en mayo de 1998 se incrementó por decreto el salario mínimo en un 9.1 por ciento, que resultó en un incremento real en ese mismo mes de 8.5 por ciento. A partir de entonces, el índice del salario mínimo real varió muy poco y, de hecho, desde diciembre de 1997 hasta diciembre de 1998, observamos que el salario mínimo real aumentó en 4.6 por ciento. A pesar de este incremento salarial, el salario mínimo es insuficiente para satisfacer las necesidades de las canasta de consumo de mercado que se utiliza para calcular el índice de precios al consumidor. Se necesitarían casi 4 salarios mínimos para cubrir la canasta de mercado, y casi 2 salarios mínimos para cubrir la canasta de alimentos" .

Esta recuperación del salario mínimo real conduce a señalar dos puntos. Primero, a pesar del incremento real del salario mínimo que oscila alrededor del 8 por ciento, no ha habido ningún cambio sustancial en los niveles de empleo y desempleo. Algunos críticos sostienen que es inadecuado aumentar el salario mínimo, puesto que no favorece a todos por igual. En particular, argumentan que un aumento del salario mínimo ocasiona una reducción en el empleo. Al menos la experiencia reciente no ha mostrado esto (con base en los datos de cotizantes al seguro social) y, por tanto, se puede argumentar que este incremento sí ha favorecido a un buen segmento de los trabajadores. Sin embargo, este incremento real no se hace efectivo en los bolsillos de los trabajadores porque una porción de este incremento se destina a las cotizaciones para los fondos de pensiones. Segundo, hay que señalar lo positivo de mantener niveles de inflación bajos - si es posible, por debajo del 5 por ciento-, dado que esto favorece a todos los trabajadores con ingresos fijos en la medida que no se deteriora mucho su poder de compra, pero éste no debe ser el objetivo final. De hecho, la última encuesta realizada por el IUDOP a finales de 1998, refleja que "en lo que se refiere a la economía, las inquietudes por el alto costo de la vida fueron sustituidas por la preocupación por el aumento de la pobreza y el desempleo"12. Dicho de otro modo, la inflación ya no aparece en las encuestas como la principal preocupación de la población, sino la pobreza y el desempleo. Si bien ha habido éxito en la estabilización de los precios, la política económica del actual gobierno no ha tenido un gran éxito en la reducción de la pobreza y el desempleo, que se manifiesta en las preocupaciones económicas de la población.

\section{Gráfico 4}

Indice de salarios reales $(1989=100)$

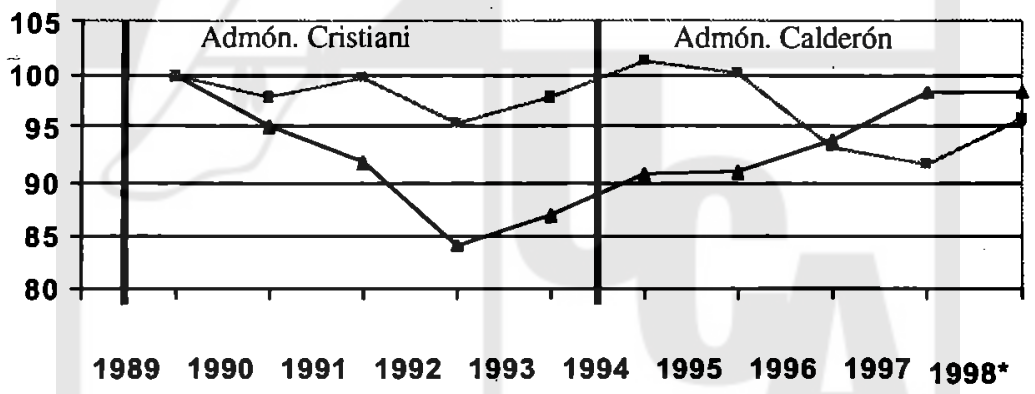

- promedio --mínimo

Fuente: elaboración propia con base en el salario mínimo y los salarios medios mensuales cotizables informados por el ISSS.

* Para 1998 se utilizó el dato correspondiente al salario promedio cotizable, reportado por la Superintendencia de Pensiones hasta noviembre de 1998.

11. Dirección General de Estadística y Censos, Ministerio de Economía.

12.IUDOP, "Evaluación del país a finales de 1998", Encuesta de opinión pública del IUDOP, enero, 1999. 
El otro aspecto sobresaliente es la evolución de los salarios reales promedios. En este sentido, la Gráfica 4 revela la evolución del salario real a lo largo de los dos períodos de gobierno presidenciales de ARENA. Entre 1989 y 1992 se registró una drástica caída en los salarios reales promedio, pero a partir de los acuerdos de paz, éstos mostraron una recuperación sostenida hasta 1997. Sin embargo, en 1998 hubo un estancamiento que contrasta con su evolución desde 1992, y su poder adquisitivo permaneció por debajo del de 1989.

\subsection{Tasas de interés nominal $y$ real $y$ el au- mento del encaje legal}

En esta sección se analizan dos aspectos: la evolución de las tasas de interés nominal y real, y la decisión del Banco Central de Reserva de incrementar el encaje legal.
A lo largo de 1998, las tasas de interés nominal han fluctuado poco, es decir, se han mantenido muy cercanas al nivel inicial. Por ejemplo, la tasa de interés en depósitos a plazo fijo por 180 días registraba 11.5 por ciento en enero y 10.74 por ciento en diciembre. De este modo, las tasas de interés tendieron a bajar un poco, pero en los últimos meses se revirtió esa tendencia y volvieron casi al mismo nivel de principios de año. El alza del último mes obedeció, en parte, al aumento de los encajes legales dispuesto por el Banco Central de Reserva. En un horizonte temporal más amplio, desde 1995 hasta 1998 se ha evidenciado una tendencia decreciente de las tasas de interés promedio. Por ejemplo, para los préstamos, la tasa de interés promedio en 1995 era alrededor del 20 por ciento, y para 1998, casi del 15 por ciento. De igual manera, las tasas de interés de los depósitos pasaron de aproximadamente 16 por ciento, en 1995, a casi un 11 por ciento, en 1998 (ver Gráfica 5).

Cuadro 8

Bancos y financieras

Tasas de interés promedio ponderada mensual para recursos en moneda nacional

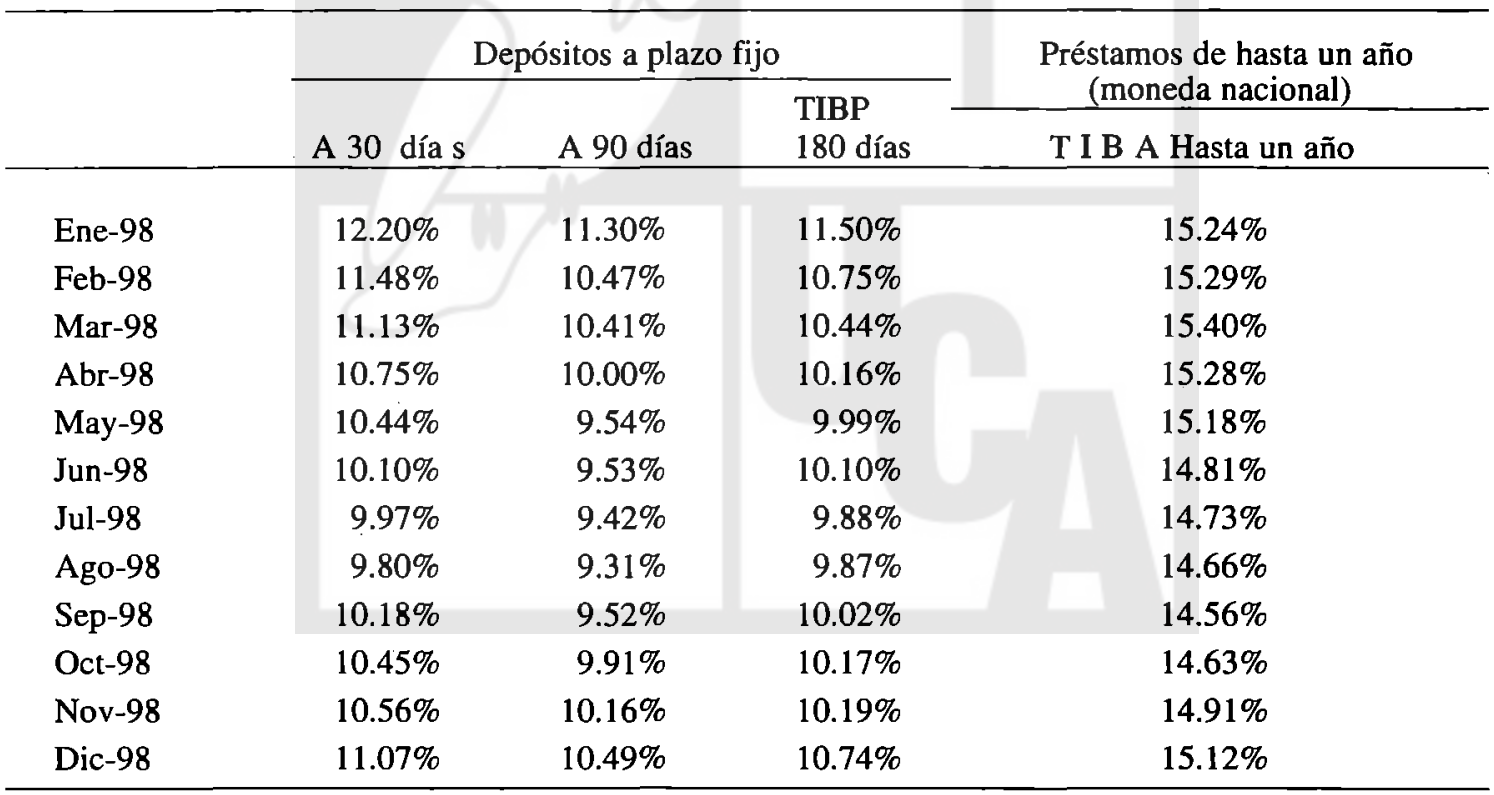

Fuente: Banco Central de Reserva. I

nternet:http://www.bcr.gob.sv/finan003.htm 
Gráfica 5

Tasas de interés activas y pasivas

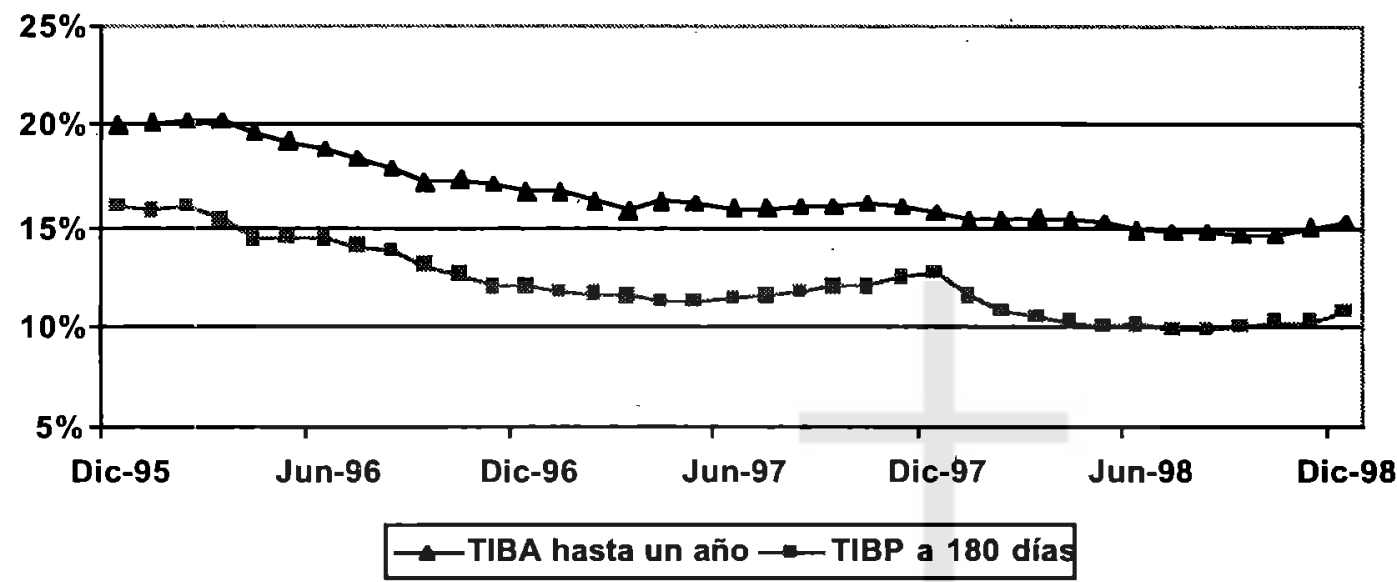

Fuente: Banco Central de Reserva.

Internet: http://www.bcr.gob.sv.

Gráfica 6

Tasas de interés reales

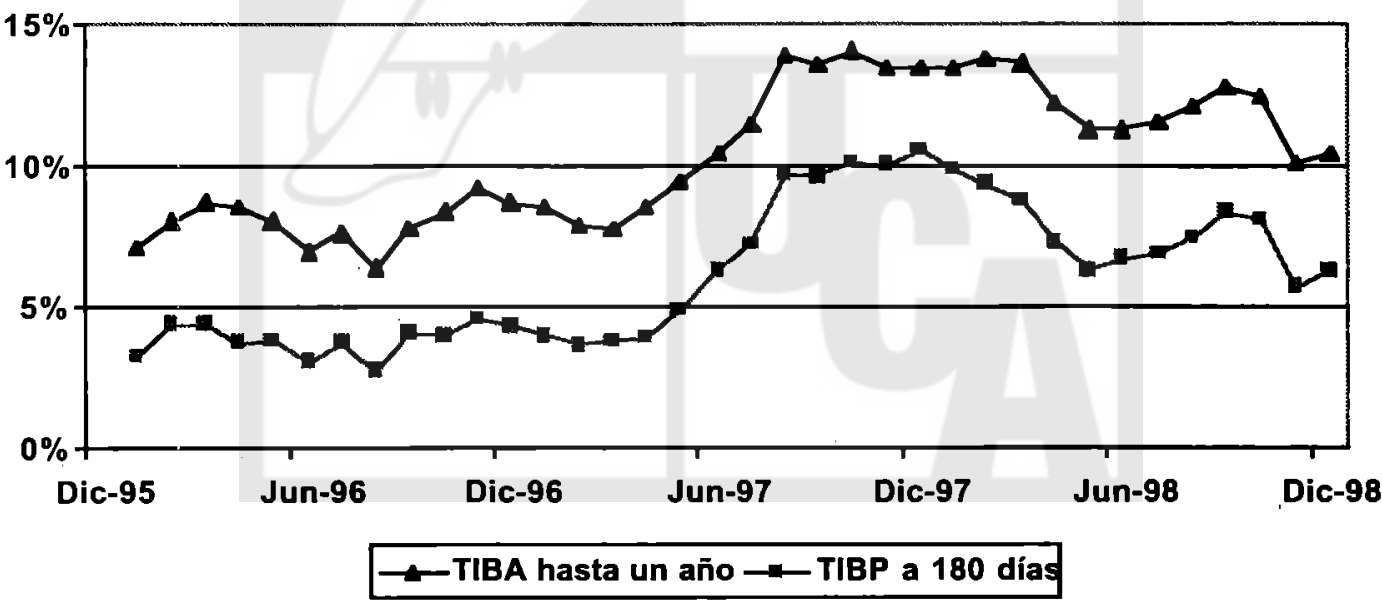

Fuente: Elaboración propia con base en los datos del Banco Central de Reserva. 
Para la evaluación de costos y beneficios, el tipo de interés real es un mejor indicador tanto para deudores como acreedores. Evidentemente, la evolución de las tasas de interés real se halla sujeta a los movimientos en la tasa de interés nominal y en la tasa de inflación. Desde 1995 hasta finales de 1997, se ha observado una reducción considerable en la tasa de inflación y, por ende, un incremento sustancial en las tasas de interés real, tanto activas (TIBA, para préstamos) como pasivas (TIBP, para los depósitos). Puesto que las tasas de interés nominal casi no variaron en 1998, la evolución de las tasas de interés real en este año ha estado dominada más por los movimientos de la inflación. Desde diciembre de 1997 hasta diciembre de 1998 se observa una tendencia decreciente en las tasas de interés real, principalmente en los últimos meses del año en que la inflación ha sido más alta.

Si la tasa de interés nominal evoluciona con la misma tendencia decreciente desde 1995, y si este año se logran mantener los niveles de la inflación, es posible prever una leve reducción en la tasa de interés real. Por supuesto, en esta previsión hay que tomar en cuenta lá decisión del Banco Central de Reserva de incrementar en 3 por ciento el coeficiente de encaje legal, a partir de noviembre pasado.

Desde finales de 1998 se ha venido planteando la preocupación por un alza en el tipo de interés, a consecuencia de esa medida. La pregunta crítica es si este incremento era necesario. En el contexto de bajos niveles de inflación y del impacto recesivo inducido en la economía por el huracán Mitch, no se logra justificar este aumento en el encaje. Sin embargo, tratando de entender los motivos de dicha política, se puede afirmar que existía un doble objetivo por parte del Banco Central de Reserva. El primero consistía en contrarrestar la fuga de divisas. Así, en los últimos meses del año, el Banco Central de Reserva se vio obligado a colocar aproximadamente 300 millones de dólares de sus reservas internacionales para mantener el tipo de cambio. El segundo sería aumentar las reservas de los bancos, en respuesta a la tendencia al deterioro en los índices de solvencia, liquidez y sanidad de la cartera, según se comenta en la sección siguiente.

\section{Evolución del sector financiero}

En relación con el sector financiero sobresalen los hechos siguientes:

- La liquidación del banco Credisa a inicios de 1999. Después de la secuela de fraudes financieros en 1997, en el sistema financiero reincide otra crisis en uno de los principales bancos del país. Para marzo de 1998, Credisa - en cuanto a número de depósitos - se encontraba entre los seis bancos más grandes de un total de 16. Este colapso evidencia algunas debilidades en el esquema de supervisión bancaria del país, al no detectar estos problemas antes que se vuelvan irreversibles. En este sentido, habría que acelerar la aprobación de las nuevas leyes que deberán regular el sistema financiero.

- Las fusiones de bancos. En è transcurso de 1998 se iniciaron varias fusiones de bancos en el país. Las más recientes son la fusión del banco de Comercio con el banco Atlacatl, y la fusión del Bancorp con Promérica.

- Otro desarrollo importante es el inicio del nuevo sistema de pensiones. Hasta noviembre de 1998, el fondo acumulado superaba los $339 \mathrm{mi}-$ llones de colones (ver Gráfica 7): Este fondo irá creciendo vertiginosamente, en la medida que se transfieran todos los afiliados al nuevo sistema y que las nuevas generaciones vayan ingresando al mercado de trabajo. Por lo tanto, desde esta perspectiva surge la necesidad de vigilar tanto al sistema financiero como a las carteras de inversión de las Administradoras de Fondos de Pensiones.

\subsection{Algunos indicadores sobre el estado actual del sistema financiero.}

Al analizar el sector financiero nos enfrentamos con dos temas importantes. Uno es el estado del sistema financiero, que se puede evaluar a partir de seis criterios: liquidez, solvencia, calidad de la cartera, crecimiento, eficiencia administrativa y rentabilidad. En este mismo orden, en el número anterior se analizó la evolución de la concentración en la industria bancaria, pero este tema se volverá a tratar en otra ocasión ${ }^{13}$.

13. Départamento de Economía, "Análisis de Coyuntura Económica", ECA, 599, septiembre, 1998. 


\section{Gráfica 7 \\ Evolución del fondo de pensiones en 1998 \\ (en millones de colones)}

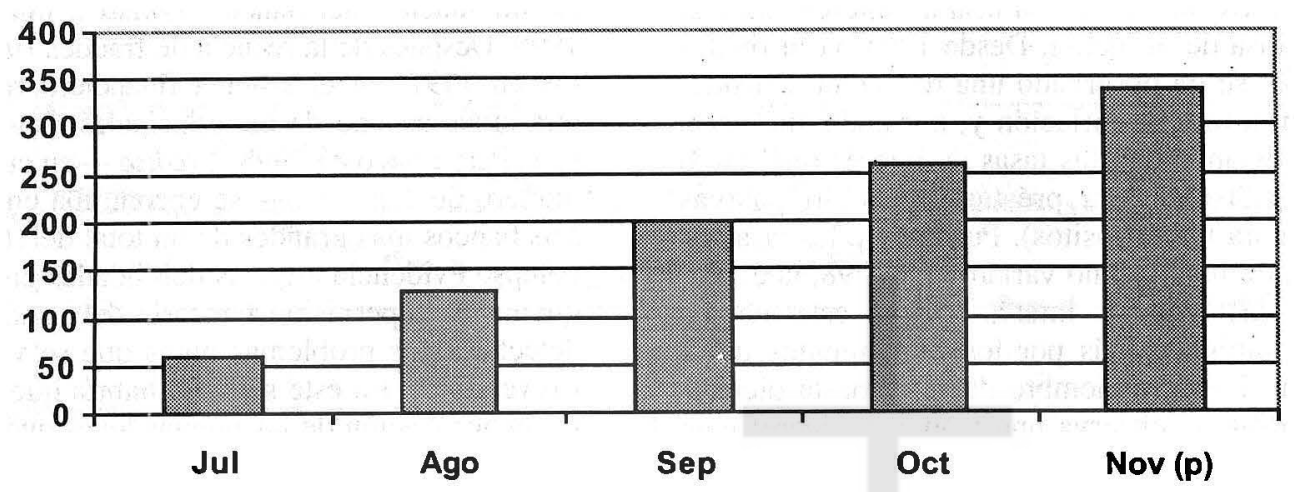

Fuente: Superintendencia de Pensiones.

\subsection{Análisis de indicadores microeconómicos del sector bancario}

Liquidez. Comenzando por el grado de liquidez $\longrightarrow$ sea, la capacidad de los bancos de cumplir con las obligaciones de corto plazo —en 1998, el sector presentó índices favorables. En efecto, el coeficiente de liquidez neta supera con cierto margen al mínimo requerido del 17 por ciento. Sin embargo, no deja de preocupar un poco la tendencia negativa en esta variable en el segundo y tercer trimestre de 1998.

\section{Cuadro 9}

Indicadores financieros de los bancos (en porcentajes)

\begin{tabular}{|c|c|c|c|c|c|c|c|c|}
\hline & Liquidez & Solvencia & & \multicolumn{2}{|c|}{ Calidad de la cartera } & & \multirow{2}{*}{\multicolumn{2}{|c|}{$\begin{array}{c}\text { Crecimientos } \\
\text { Anuales }\end{array}$}} \\
\hline & & & & \multirow{2}{*}{$\begin{array}{l}\text { Morosidad } \\
\text { Préstamos } \\
\text { vencidos/ } \\
\text { préstamos brutos }\end{array}$} & \multicolumn{2}{|c|}{ Riesgo crediticio } & & \\
\hline & $\begin{array}{l}\text { Coeficiente de } \\
\text { líquidez nela }\end{array}$ & $\begin{array}{l}\text { Fondo patrimonial/ } \\
\text { aclivos ponderados }\end{array}$ & $\begin{array}{l}\text { Fondo patrimonial/ } \\
\text { pasivos más } \\
\text { conlingencias }\end{array}$ & & $\begin{array}{l}\text { Carlera "D" y } \\
\text { "E"/Total de activos } \\
\text { de riesgo brutos }\end{array}$ & $\begin{array}{l}\text { Reservas de } \\
\text { saneamiento/ } \\
\text { aclivos de riesgo } \\
\text { brutos }\end{array}$ & Depósitos & $\begin{array}{c}\text { Aclivos } \\
\text { tolales }\end{array}$ \\
\hline Mar-97 & $25.70 \%$ & $10.50 \%$ & $8.02 \%$ & $4.36 \%$ & $3.32 \%$ & & $11.90 \%$ & $11.81 \%$ \\
\hline Jun-97 & $27.09 \%$ & $10.50 \%$ & $8.13 \%$ & $3.89 \%$ & $3.56 \%$ & $3.26 \%$ & $13.25 \%$ & $11.61 \%$ \\
\hline Sep-97 & $25.81 \%$ & $10.57 \%$ & $8.31 \%$ & $4.13 \%$ & $3.52 \%$ & $3.31 \%$ & $9.28 \%$ & $10.23 \%$ \\
\hline Mar-98 & $28.06 \%$ & $10.16 \%$ & $7.77 \%$ & $4.25 \%$ & $3.71 \%$ & $3.67 \%$ & $16.77 \%$ & $16.32 \%$ \\
\hline Jun-98 & $26.78 \%$ & $10.32 \%$ & $7.96 \%$ & $4.50 \%$ & $3.77 \%$ & $3.68 \%$ & $14.06 \%$ & $16.05 \%$ \\
\hline Sep-98 & $24.78 \%$ & $10.08 \%$ & $7.96 \%$ & $4.81 \%$ & $3.67 \%$ & $3.39 \%$ & $13.71 \%$ & $15.20 \%$ \\
\hline
\end{tabular}

Fuente: Superintendencia del Sistema Financiero.

Solvencia. Para evaluar la solvencia del sistema bancario o de los bancos particulares se cuenta con dos indicadores. El primero es la razón del
Fondo Patrimonial entre los Activos Ponderados que, de acuerdo con la Ley de Bancos y Financieras, debe representar en todo tiempo un mínimo de 
8.9 por ciento, y de conformidad con el Comité de Basilea. Para este indicador se observa que el sistema bancario en su conjunto cumple con dicho requisito, pero del primer trimestre de 1997 al tercer trimestre de 1998 se observa una tendencia negativa. El segundo indicador es el Fondo Patrimonial sobre los Pasivos más Contingencias y, de acuerdo con la Ley de Bancos y Financieras, este coeficiente no podrá ser inferior al 5 por ciento. Se observa que también cumple con los requisitos establecidos y su variación no es muy alta, pero al igual que el otro indicador de solvencia financiera muestra una tendencia a la baja.

Calidad de la cartera. En relación con la calidad de la cartera se emplean 3 indicadores. El primero corresponde a la morosidad, medida por el coeficiente de préstamos vencidos entre préstamos brutos. Para todos los bancos, pasó de 4.36 por ciento en marzo de 1997 a 4.81 por ciento en septiembre de 1998. Un incremento rápido de este in- dicador es una señal clara de peligro ${ }^{14}$. Sin embargo, hasta el momento, el incremento parece ser moderado. Ahora bien, existe el problema de la veracidad de la información proporcionada por los bancos, tal como lo muestra el caso Credisa, que al ser inspeccionado en mayor detalle se fueron descubriendo niveles de morosidad más altos. Por ejemplo, utilizando los datos disponibles, entre marzo de 1997 y septiembre de 1998, la morosidad de la cartera se duplicó en el Banco Credisa, pasando de 4.15 por ciento en marzo de 1997 a 8.51 por ciento en septiembre de 1998 (ver Gráfica 8). Acá se formulan las interrogantes críticas siguientes: ¿Cómo puede duplicarse en dieciocho meses la morosidad de un banco? ¿Fue por un deterioro no anticipado en los sectores a los que dirigió los créditos? ¿Fue porque poco a poco se fue descubriendo la mala calidad de su cartera? Si fue esto último, hay claramente problemas de transparencia en la información suministrada por los bancos.

\section{Gráfica 8}

Morosidad de la cartera en CREDISA

(préstamos vencidos/préstamos brutos)

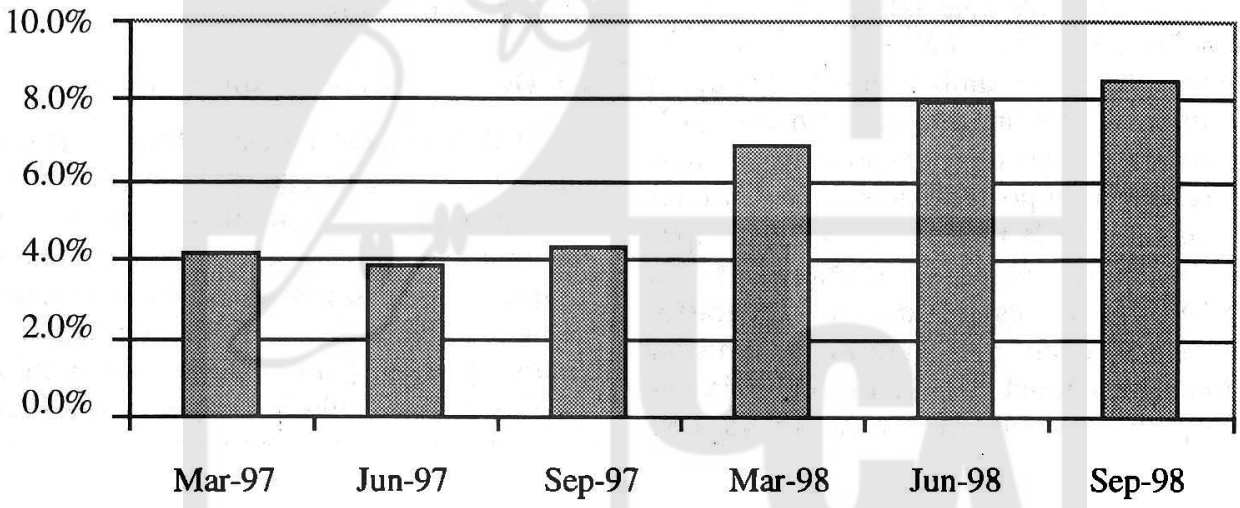

Fuente: Superintendencia del Sistema Financiero.

Otra forma de evaluar la calidad de la cartera es mediante el riesgo crediticio, para el cual se utilizan dos razones. El primer ratio se refiere al porcentaje de activos de riesgo, medida por el porcentaje de préstamos de difícil recuperación (cate- goría "D") y préstamos irrecuperables (categoría "E"). Este indicador presenta, en general, un leve deterioro de la calidad de la cartera, ya que pasó de 3.32 por ciento en marzo de 1997 , a 3.67 por ciento en septiembre de 1998. El segundo corres-

14. Hardy, Daniel C., "Are Banking Crisis Predictable", Finance and Development, 4, Vol. 35, Washington, D.C., diciembre, 1998. 
ponde al porcentaje de reservas de saneamiento para afrontar cualquier problema que presenten los préstamos de alto riesgo. También se observa un incremento en las reservas de saneamiento, que es una medida adecuada dado el incremento de créditos de riesgo.

Finalmente, se evalúa el crecimiento anual de los depósitos y de los activos de los bancos, que en ocasiones pueden servir de aviso sobre posibles problemas en el sistema bancario. Tanto los depósitos como los activos totales han crecido a tasas elevadas, pero consideradas dentro de un rango normal. Lo que sí puede ser una razón de preocupación más importante es la relación depósitos y préstamos.

\section{Reflexiones sobre la dolarización}

A lo largo de 1998 se han manifestado, en repetidas ocasiones, disgustos sobre el manejo de la política monetaria y cambiaria. Más recientemente, ha resurgido la idea de la dolarización de la economía salvadoreña. Antes de proseguir, vale la pena aclarar: ¿qué es la dolarización? ¿Cuáles son sus ventajas y desventajas?

La dolarización es un arreglo cambiario y monetario, bajo el cual un país adopta el dólar de Estados Unidos como moneda y cumple con sus tres funciones: medio de cambio, unidad de cuenta y depósito de valor. Es un arreglo cambiario, porque se elimina el riesgo de variaciones en el tipo de cambio (es decir, la posibilidad de una devaluación o revaluación de la moneda nacional desaparece), por el hecho de que la moneda nacional deja de existir. Asimismo, es un arreglo monetario, porque un país renuncia a su derecho de emisión de una moneda nacional. Por tanto, también renuncia a la política monetaria. En definitiva, con la dolarización un país sacrifica dos instrumentos de la política económica para estabilizar la economía ante perturbaciones externas: el tipo de cambio y la oferta de dinero.

\subsection{Ventajas de la dolarización}

La dolarización es una medida extrema para recuperar la credibilidad de las autoridades monetarias, en su compromiso para combatir la inflación. En realidad muy pocos países la han adopta- do. En la actualidad, los únicos países que carecen de moneda nacional son Panamá y Liberia. Lo más común para combatir la inflación ha sido la adopción del esquema de caja de conversión. Hoy en día existen en el mundo 14 países en que opera una caja de conversión, entre ellos Argentina y Hong Kong ${ }^{15}$. Este arreglo se diferencia de la dolarización plena en que se mantiene la moneda nacional, completamente respaldada por una moneda "ancla" - normalmente el dólar-, pero el riesgo cambiario permanece por la existencia de la moneda nacional. En este sentido, ambos esquemas son muy parecidos, pero se diferencian en el grado de riesgo cambiario. En todo caso, la idea no es nada nueva, de hecho, con el patrón oro ya ha funcionado un esquema muy similar a la dolarización.

Entre quienes propician o apoyan la dolarización se encuentran los argumentos siguientes: $(a)$ el aumento de la credibilidad de la política económica para combatir la inflación, $(b)$ la reducción de la inflación y la tasa de interés a los niveles que persisten en Estados Unidos, (c) la desaparición total del riesgo cambiario que favorece la inversión extranjera y el crecimiento, y $(d)$ mayor disciplina fiscal por parte del gobierno en vista de que no podrá recurrir a la emisión monetaria para financiar los déficits.

\subsection{Desventajas de la dolarización}

La dolarización no está libre de críticas: (a) el país limita su capacidad para incidir en la tasa de cambio real, lo que implica aceptar un proceso más largo de ajuste con desempleo y recesión ante choques externos, como una caída drástica de los precios del café; $(b)$ se renuncia al uso del tipo de cambio nominal para absorber desequilibrios monetarios; $(c)$ se anula la capacidad del Banco Central para intervenir como prestamista de última instancia; y (d) no existe garantía de que se sigan políticas fiscales consistentes. Adicionalmente, algunos críticos argumentan que no es una política irreversible, las leyes pueden cambiar. De estos, la crítica más fuerte es la prolongación de un ajuste ante un choque externo (caída en los precios de nuestras exportaciones, alza de la tasa de interés internacional, aumento en los precios del petróleo, etc.), ya que esto implica períodos de desempleo más largo o ajustes en los salarios reales a la baja,

15. Ver Enoch y Gulde (1998) para un breve tratado sobre las cajas de conversión. 
sin que las autoridades monetarias puedan hacer nada para estimular la economía.

\subsection{La dolarización se pone de moda}

Con la reciente turbulencia en los mercados financieros internacionales -donde se dan ataques especulativos a las monedas de economías emergentes- está creciendo el clamor por una mayor estabilidad mediante la adopción de ésquemas, como la caja de conversión o la dolarización completa. A raíz de la agudización de la crisis brasileña en enero de 1999, el presidente Argentino Carlos Menem ha pedido a su grupo de asesores económicos que estudie la posibilidad de adoptar la dolarización plena en Argentina, que ya funciona con una caja de conversión. Por su parte, el Ministro de Finanzas mejicano, José Angel Gurria, en el Foro Económico Mundial en Davos dijo que México no apostará por la dolarización, pero la opinión pública mexicana está a favor de la eliminación del peso, y líderes empresariales desde hace un tiempo están considerando seriamente la dolarización de México.

En El Salvador ha comenzando a aparecer en los periódicos del país la idea de la dolarización, pero no es la primera vez que se habla del tema. El tema de la dolarización no es nuevo en El Salvador, ya que se puso en el tapete de discusión en 1994. Melhado $(1997$, p. 97) señala que el actual Ministro de Hacienda, Manuel Hinds, ya para octubre de 1994 sugería la adopción de un tipo de cambio fijo, y tenía en cuenta la posibilidad de una caja de convertibilidad o la dolarización plena, pero no mostraban una decisión definitiva. Para noviembre de ese año, esta propuesta, junto a otras medidas como la desgravación arancelaria, se presentó en Washington ante los organismos internacionales que lo recibieron con esceptisismo.

Uno de los argumentos a favor era que con el tipo de cambio fijo implementado a través de una caja de conversión, como la de Argentina, las tasas de interés bajarían. En Washington se recomendó no seguir en esta línea, pero al regresar a El Salvador se siguió con la idea de la dolarización plena de la economía. La idea había sido tomada muy seriamente por los arquitectos de aquel plan de política económica a tal grado, que se llegó a niveles de discusión técnica bien altos, con el propósito de asentar los detalles de su implemen-

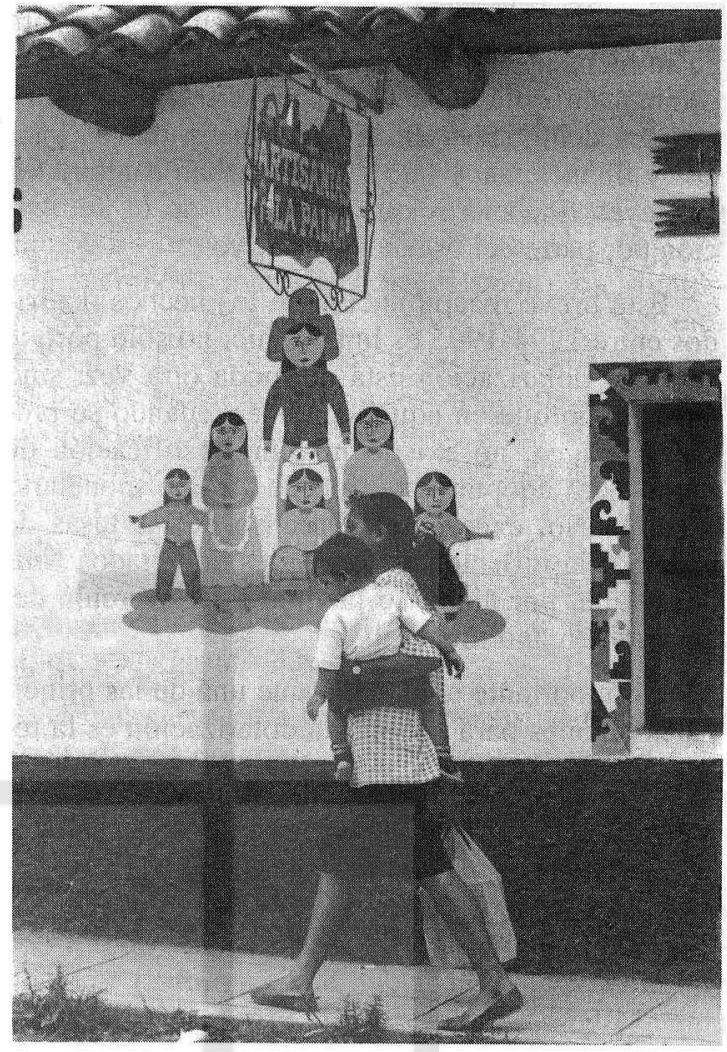

tación. El grado de la discusión técnica se mantuvo en la confidencialidad, y se invitó a un grupo consulta del Fondo Monetario Internacional (FMI) que permaneció en el país del 30 de enero al 15 de febrero de 1995, para asistir el nuevo arreglo monetario y cambiario que se pretendía implementar. También se tuvo una visita del Departamento Legal del FMI entre el 29 de marzo y el 4 de abril, "para analizar los aspectos legales de las reformas bajo estudio", para lo cual ya se contaba con un "Proyecto de Ley de Convertibilidad".

En enero de 1995 se anunció la medida en la Cámara de Comercio, pero a mediados de año, la fuerte oposición por parte del sector privado, principalmente los industriales y agricultores, y la afirmación del gobierno de que su implementación no iba a ser tan fácil a corto plazo, provocaron que se dejara de lado esta opción y se decidió por adoptar un tipo de cambio fijo y permitir la coexistencia del dólar con el colón. Entre las dificultades que se enfrentaron en aquel entonces, aparte de la oposición política, están el que El Salvador no conta- 
ba con las reservas internacionales suficientes para su implementación ${ }^{16}$, que las finanzas públicas no estaban en orden, que el sistema financiero presentaba debilidades en la supervisión de los bancos y financieras, y que se necesitaban cambios en las leyes financieras que requerían de la aprobación por parte del órgano legislativo.

Esta breve recapitulación de los hechos ocurridos entre 1994-1995 es importante, no sólo porque ahora la dolarización está de moda otra vez, sino también porque en aquel entonces, cuando se presentó la idea, no existió ninguna justificación de fondo para adoptar este tipo de arreglo monetario y cambiario, excepto el descenso de las tasas de interés y la inflación a los niveles de Estados Unidos y que, por tanto, se facilitaría la inserción del país al mercado mundial.

Es importante considerar que una de las principales razones para adoptar la dolarización es la re- ducción de la inflación. Sin embargo, en los últimos dos años, el Banco Central ha tenido éxito en la reducción de la inflación, por lo que no se justificaría desde este flanco una medida tan extrema como la dolarización. También, gracias al flujo de remesas familiares y a la entrada neta de capital extranjero al país, se ha logrado mantener un tipo de cambio fijo y un incremento permanente de las reservas internacionales netas (RIN) del Banco Central de Reserva que, en 1995, representaban 2/3 de la base monetaria, y que en noviembre de 1998 , las Remesas Internacionales Netas cubrían el 113.3 por ciento de la base monetaria. Esto último le da solidez al tipo de cambio que se ha sostenido $y$, por tanto, por el flanco de la credibilidad tampoco se visualiza una justificación para la dolarización, a menos que existan temores de que gobiernos futuros se vuelvan menos estrictos con la política monetaria.

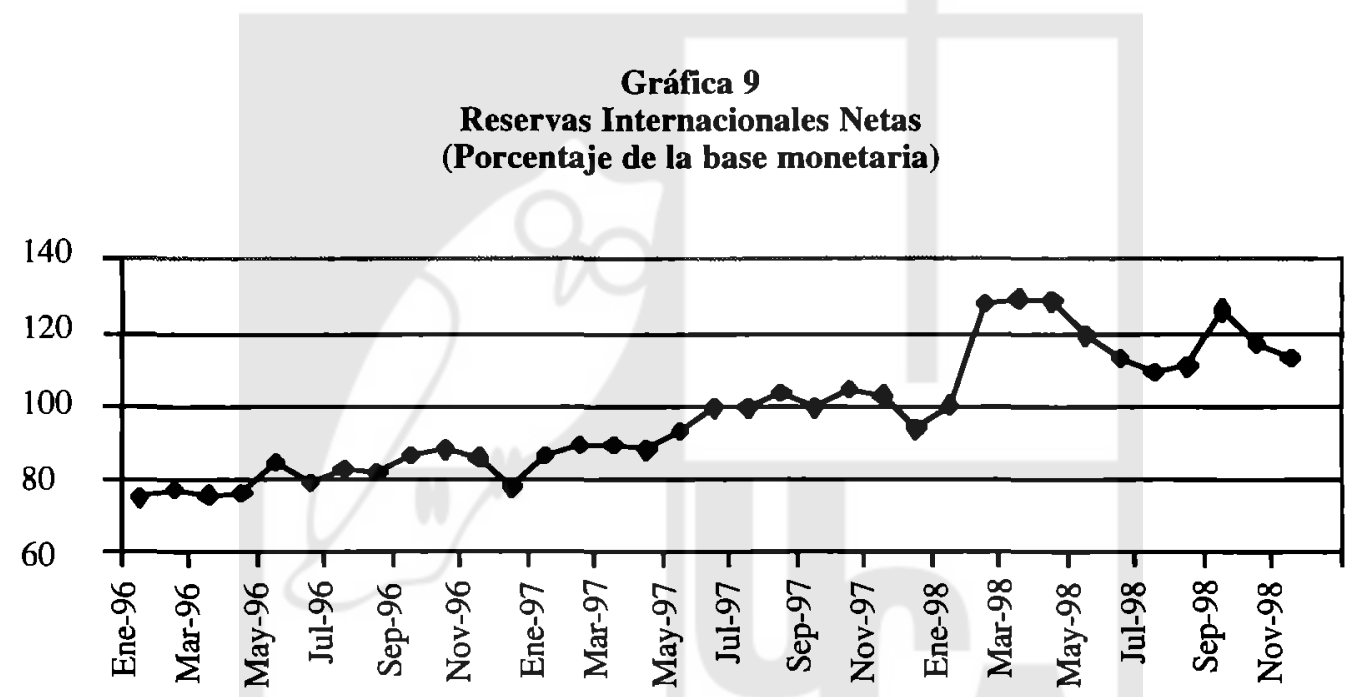

Fuente: Banco Central de Reserva, Boletín Estadístico Mensual.

Además, debido a los fuertes lazos comerciales que existen con Estados Unidos y la cantidad enorme de salvadoreños que viven en aquel país, El Salvador ha experimentado un proceso de sustitución de monedas, ya que cada vez más los agen- tes económicos tienen una proporción de sus activos monetarios en dólares, lo que hace notar que de hecho ya existe una dolarización parcial de la economía, pero sin las desventajas que implica una dolarización total. Este hecho se evidencia

16. Aunque en un memo confidencial, el ministro Hinds ingeniosamente argumenta que El Salvador sí contaba con las reservas suficientes, parece que el Fondo Monetario Internacional no opinaba lo mismo. Sobre este aspecto, ver Melhado (1997). 
con la evolución de los depósitos en moneda extranjera como proporción del agregado monetario M2, que pasó de casi un 5 por ciento a finales de 1995 a un 8.4 por ciento a septiembre de 1998 .

\section{Gráfica 10 \\ Depósitos en moneda extranjera como proporción del agregado monetario M2}

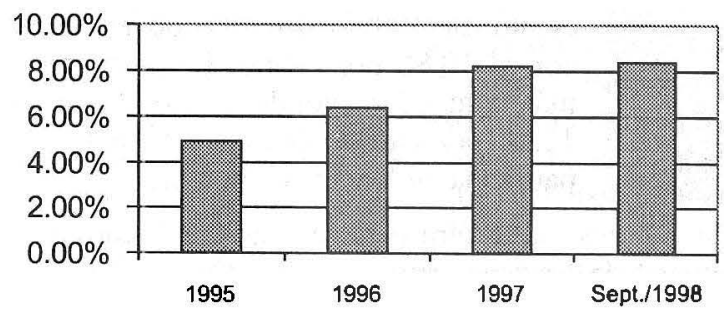

Fuente: Banco Central de Reserva, revista trimestral.

Por otro lado, aunque algunos sostienen que una de las ventajas de la dolarización es que pone disciplina a la política fiscal, otros sostienen que debe ser lo contrario. El éxito de la dolarización depende del buen manejo que se haga de las finanzas públicas. En este sentido, el país no está preparado para la dolarización total. Al finalizar 1998, el déficit fiscal representaba 2.3 por ciento del Producto Interno Bruto, y para 1999 se anticipa un déficit del 2.5 por ciento del Producto Interno Bruto, en el programa monetario y financiero del Banco Central. Si bien los estándares internacionales sostienen que un déficit fiscal por debajo del 3 por ciento es prudencial, en el país existe preocupación por parte del sector privado y de varios economistas sobre la apertura del déficit fiscal, y el creciente endeudamiento externo del gobierno.

Por otra parte, para poner disciplina fiscal no se necesita recurrir a la medida extrema de una dolarización total. De hecho, esta imposición a la disciplina fiscal ya está explícita en la reforma al artículo 111 de la Constitución de 1983, aprobada en abril de 1997 (Diario Oficial, 15 de mayo de
1997, No. 87, Tomo 335, p. 8), que indica que el Banco Central "no podrá financiar directa o indirectamente al Estado, ni a las instituciones y empresas estatales de carácter autónomo, ni a los Municipios, ni adquirir documentos o valores emitidos por el Estado y estas instituciones. Así mismo no podrá otorgar avales, fianzas o garantías por obligaciones contraídas por el Estado, los Municipios y las mencionadas instituciones..." Sin embargo, dicha reforma aún no ha sido ratificada por la actual asamblea legislativa. No obstante, en la actualidad, el Banco Central tiene prohibido prestar al gobierno de acuerdo con la Ley Orgánica del Banco Central. Por tanto, esta justificación para adoptar una dolarización total tampoco es válida en nuestro país. Para que exista disciplina fiscal, el gobierno tiene que tener la voluntad política de ajustar sus gastos a sus ingresos.

Finalmente, otro requisito indispensable para el éxito de una dolarización total es un sistema financiero sano. Como hemos visto en 1997 y 1998, los casos Insepro-Finsepro, Crediclub y Credisa muestran serias debilidades en la supervisión de los bancos y financieras, que no logran detectar a tiempo las anomalías de las instituciones financieras. Por tanto, antes de hablar de dolarización hay que avanzar más en el fortalecimiento del sistema financiero.

\section{4. ¿Es conveniente la dolarización?}

La dolarización total de la economía es una medida extrema que generalmente se adopta para garantizar el éxito de una política antiinflacionaria, después de repetidos y fallidos intentos de reducción de la inflación, con la consecuencia de que el país pierde flexibilidad en sus instrumentos de política económica para contrarrestar choques externos y realizar los ajustes macroeconómicos necesarios. En nuestro país, el sistema de tipo de cambio fijo parece haber tenido éxito en la reducción de la inflación, y los niveles de reservas internacionales muestran un grado de solvencia externa envidiable para muchos países latinoamericanos. De hecho, la disciplina fiscal que se puede alcanzar con la dolarización ya se ha impuesto con la 


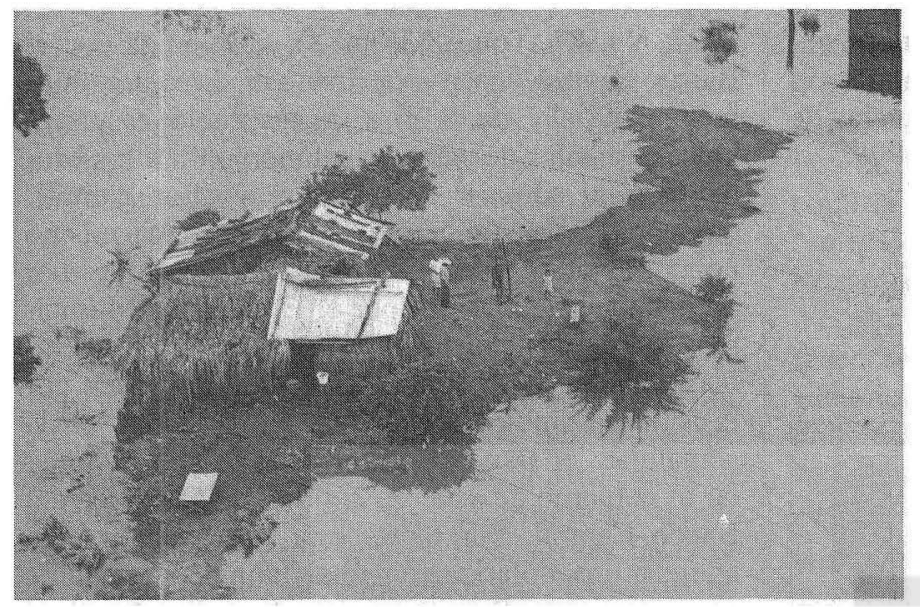

do en forma reiterada que la corrupción se encuentra generalizada entre los contribuyentes.

En tales condiciones, la carga tributaria - la fracción del Producto Interno Bruto recolectada en concepto de impuestos- se mantiene en una proporción considerada como baja. Así, entre 1989 y 1996 se registra un promedio de 9.70 por ciento, a partir del 7.62 por ciento en 1989 y finalizando en 1998 con el 10.80 por ciento. La proporción más alta corresponde a 1995 con el 12.04 por ciento, declinando en forma paulatina en los años siguientes.

Por otra parte, la carga tributaria po-

Ley Orgánica del Banco Central. Además, el sistema financiero necesita de reformas pendientes para su fortalecimiento. El único argumento válido sería si la dolarización va a servir para inducir al país a una mejor inserción en el mercado mundial, a más inversión y crecimiento económico, de manera que se mejoren las condiciones de vida de la gran mayoría de la población. Es algo que se debe estudiar con mayor profundidad antes de proceder a su implementación.

\section{EI sector público}

\subsection{Carga tributaria y evasión fiscal}

En El Salvador prevalece una cultura de evasión fiscal. Esta problemática, ampliamente reconocida en la sociedad, repercute profundamente en la capacidad del gobierno para desarrollar sus funciones. El Ministro de Hacienda ha señalado, en varias ocasiones, que representa un problema de grandes proporciones. En octubre de 1996, ante la Comisión de Hacienda de la asamblea, declaró que el IVA se evade por arriba del 50 por ciento y de la gravedad de la evasión del impuesto sobre la renta y el contrabando. Por su parte, el Director de Impuestos Internos manifestó que un 60 por ciento de los contribuyentes, que forman parte de la base tributaria, evaden impuestos (es decir, no pagan lo que les corresponde) ${ }^{17}$. En el marco de la actual campaña electoral, la opinión pública ha expresa- tencial de las leyes tributarias vigentes en el país se ha calculado entre 18 y 20 por ciento, respectivamente, del Producto Interno Bruto. De allí que, en la práctica, se evade entre 7.2 y 9.2 por ciento, respectivamente, del Producto Interno Bruto, una alta proporción con respecto a la carga tributaria efectiva. De acuerdo con el Ministerio de Hacienda, la evasión de impuestos internos en 1996 se calculó en 3.32 por ciento del Producto Interno Bruto y en 3.23 por ciento en 1997. Los hechos indican la insuficiencia de los esfuerzos del Ministerio de Hacienda para controlar esta excesiva evasión. Sin embargo, se detectó una mejoría en la efectividad por caso fiscalizado, de 6,316 colones en 1997 a 10,865 colones en 1998. En 1997 hubo un total de 22,622 casos fiscalizados, reduciéndose casi a la mitad en 1998 , con $11,838^{18}$. A diferencia de años anteriores, cuando se ejerció cierta presión para el control del IVA cobrado y no remitido al fisco, en 1998 este esfuerzo pareció mínimo. Todo parece indicar que surtieron efecto las presiones de las gremiales empresariales, que criticaron dicha medida como "acoso fiscal".

En comparación con otros países de América Latina, la carga tributaria salvadoreña es una de las más bajas. En 1996, el promedio latinoamericano registró el 13.4 por ciento, y en nuestro país fue el 11.5 por ciento. Brasil estuvo entre 23 y 24 por ciento, Nicaragua cerca del 20 por ciento, Costa Rica arriba del 17 por ciento, Honduras aproxi-

17. Noticia que apareció en El Diario de Hoy, el 5 de octubre de 1998.

18. Ministerio de Hacienda, "Principales actividades de 1998 y Planes de Fiscalización para 1999 de la Dirección General de Impuestos Internos", San Salvador, enero, 1999. 
madamente un 15 por ciento; y en Centroamérica, sólo Guatemala con el 10 por ciento presentó una presión inferior a la nuestra.

Como queda en evidencia, el Gobierno Salvadoreño en este plano es débil. De modo que desde la política fiscal -es decir, utilizando el presupuesto en su forma integral como una relación de ingresos y egresos públicos- poco es lo que se puede hacer para enfrentar de forma eficiente $y$ eficaz los ingentes problemas de pobreza, marginación social, deterioro del medio ambiente, problemas educativos, de salud y otros. Por tanto, el presupuesto no puede ser visto como una simple relación de ingresos y egresos, sino a partir de sus vinculaciones con la función que la Constitución le confiere al sector público. En este sentido, la baja carga tributaria guarda correlación directa con el deterioro social en que vivimos.

Una medida de la eficacia del IVA está definida por el copciente entre la tasa IVA colectado/consumo nacional y la tasa del IVA. Dada una tasa del IVA del 13 por ciento, y una tasa del 5.85 por ciento de IVA colectado/consumo nacional, se obtiene un índice de eficacia del 45 por ciento para 1996. En 1997, este índice subió a 47 por ciento. Estos resultados indican que el fisco deja de perci- bir más del 50 por ciento del potencial de la tasa del 13 por ciento del IVA. Es decir, se diluye entre evasión y elusión ${ }^{19}$. Ante esta situación, es imperativo revisar el marco de exenciones y disposiciones de la ley del IVA.

La incidencia de la evasión en el impuesto sobre la renta se puede visualizar a partir de los datos del Cuadro 10. Entre 1995 y 1997 disminuyó el número de personas naturales que presentaron declaración de la renta con impuesto a pagar, al pasar de 38,743 a 32,373 , lo que implicó una reducción del orden del 16.4 por ciento. El dato que sorprende es que en 1995 sólo 3,284 personas declararon renta imponible arriba de 200,000.00 colones, y 4118 en 1997. Esto implica que en El Salvador apenas 4,118 personas manifestaron tener un ingreso promedio mensual de 20,000 colones o más. Con respecto al impuesto sobre la renta para personas jurídicas, de 1995 a 1997 disminuyó en 493 el número de empresas que declararon pagar renta ${ }^{20}$. En 1995 se registraron 2,998 empresas que declararon rentas imponibles superiores a 75,000 colones, y en 1997, un número de 2,505 , lo que significa una reducción del 16.4 por ciento.

Combinando los datos anteriores con los del Cuadro 11, se observa que entre 1995 y 1997, los

\section{Cuadro 10}

\section{Contribuyentes con monto a pagar en la declaración de renta}

1995-1997

(en millones de colones)

\begin{tabular}{|c|c|c|c|c|c|c|c|c|c|}
\hline \multirow[b]{3}{*}{ Rango según renta imponible } & \multicolumn{3}{|c|}{199.5} & \multicolumn{3}{|c|}{1996} & \multicolumn{3}{|c|}{1997} \\
\hline & Contribuyentes & \multirow{2}{*}{$\begin{array}{l}\text { Impuesto } \\
\text { compulado }\end{array}$} & \multirow{2}{*}{$\begin{array}{l}\text { Impuesto } \\
\text { pagado }\end{array}$} & \multirow[t]{2}{*}{ Contribuyentes } & \multirow{2}{*}{$\begin{array}{l}\text { Impuesto } \\
\text { computado }\end{array}$} & \multirow{2}{*}{$\begin{array}{l}\text { Impuesto } \\
\text { pagado }\end{array}$} & \multirow[t]{2}{*}{ Contribuyentes } & \multirow{2}{*}{$\begin{array}{l}\text { Impieslo } \\
\text { compulado }\end{array}$} & \multirow{2}{*}{$\begin{array}{l}\text { Impuesio } \\
\text { pagado }\end{array}$} \\
\hline & & & & & & & & & \\
\hline \multicolumn{10}{|l|}{ Personas nalurales } \\
\hline Menor a 0.00 & 376 & 492,866 & 443,225 & 136 & 53,305 & 52,555 & 39 & 660,958 & 867427 \\
\hline De 0,00 a 22,000 & 2,221 & $8,853,871$ & $7,264,123$ & 783 & $2,509,854$ & 837,666 & 392 & $1,402,101$ & 662,626 \\
\hline De 22,000 a 80,000 & 26,281 & $75,620,729$ & $38,044,958$ & 23,586 & $66,986,211$ & $28,073,573$ & 20,728 & $62,578,366$ & $28,024,843$ \\
\hline De 80,000 a 200,000 . & 6,581 & $101,669,291$ & $46,793,372$ & 6,548 & $97,583,505$ & 7,096 & $108,314,463$ & $41,853,943$ & \\
\hline Arriba de 200,000 & 3,284 & $331,126,387$ & $120,116,795$ & 3,624 & $344,226,1.56$ & $106,966,812$ & 4,118 & $422,373,739$ & $138,897,488$ \\
\hline Subtotal & 38,743 & $517,763,144$ & $212,662,473$ & 34,677 & $511,359,031$ & $176,056,4.31$ & 32,373 & $595,329,627$ & $210,306,327$ \\
\hline Personas juridicas & 2,998 & $1,127,195,676$ & $486,982,169$ & 2,387 & $1,098,703,615$ & $590,024,698$ & 2,505 & $1,096,715,094$ & 518897188 \\
\hline Total & 41,741 & $1,644,958,823$ & $699,644,541$ & 37,064 & $1,610,062,646$ & $766,081,129$ & 34,878 & $1,692,044,721$ & $729,203,515$ \\
\hline
\end{tabular}

Fuente: Ministerio de Hacienda, Dirección General de Impuestos Internos.

19. La elusión fiscal, al igual que la evasión, es no pagar los impuestos que se deben al Estado, pero se diferencia en que se ampara en vacíos legales para no pagar.

20. La Ley de Impuesto sobre la Renta indica que aquellas empresas que tengan renta imponible inferior a los 75,000 colones están exentas de pago. 
grandes contribuyentes pasaron de 1,077 a 1,070, y los medianos, de 4,384 a 4,336 . Entre ambas categorías se reduce el número de contribuyentes en 55, lo que representa una disminución del 1 por ciento. En este sentido surge la interrogante siguiente: ¿Cómo se explica que los contribuyentes del IVA disminuyan en 1 por ciento y las empresas que pagan impuesto sobre la renta, en un 16.4 por ciento? Esta situación sugiere que se ha incrementado la evasión en el impuesto a la renta, o bien, que ciertas actividades económicas han dejado de ser lucrativas.

\section{Cuadro 11 \\ IVA pagado por cartera de contribuyentes 1995-1997 \\ (en millones de colones)}

\begin{tabular}{lrrrrrrrr}
\hline & \multicolumn{2}{c}{1995} & & \multicolumn{2}{c}{1996} & & \multicolumn{2}{c}{1997} \\
\cline { 2 - 3 } & Contribuyentes & Impuesto & & Contribuyentes & Impuesto & Contribuyentes & Impuesto \\
\hline Grandes & 1,077 & $1,531.62$ & & 1,072 & 1,792 & & 1,070 & $1,884.59$ \\
Medianos & 4,384 & 434.93 & & 4,361 & 503 & & 4,336 & 489.26 \\
Pequeños & 51,505 & 258.68 & & 56,045 & 430 & & 59,503 & 552.24 \\
\hline Total & 56,966 & $2,225.23$ & & 61,478 & $2,725.01$ & & 64,909 & $2,926.09$ \\
\hline
\end{tabular}

Fuente: Ministerio de Hacienda, Dirección General de Impuestos Internos.

\subsection{El peso fiscal de la privatización del siste- ma de pensiones}

En perspectiva, la privatización del sistema de pensiones, en vigencia desde abril de 1998, ejercerá uña presión considerable sobre el presupuesto nacional. La CEPAL advierte que una de las dificultades más complicadas para el Gobierno consiste en cubrir el monto de los Certificados de Traspaso de los afiliados del sistema de pensiones del ISSS e INPEP, que se incorporarán al nuevo sistema.

La CEPAL ha calculado que el nivel de deuda previsional con cargo al presupuesto será elevada y se hallará sujeta a varios factores, entre ellos a su significación dentro del Producto Interno Bruto. "El cambio total e instantáneo hacia cuentas de ahorro individuales obligatorias implica reconocer dos componentes de la deuda previsional: (a) el valor presente de las pensiones de quienes se encuentran presentes pensionados a la fecha de vigencia de la reforma (la deuda previsional de los jubilados); y (b) el valor presente de las contribu- ciones (o beneficios a los cuales dan derecho) que hasta la fecha de vigencia de la reforma han realizado (adquirido) aquellos que aún permanecen activos (la deuda previsional con los activos). La suma de ambos valores, menos el valor de las reservas del sistema antiguo, constituye una aproximación de la deuda previsional implícita... Para un primer grupo de países, cuya deuda previsional se estima sobre 200 por ciento del Producto Interno Bruto... implica recursos fiscales por un monto superior a 6 por ciento del Producto Interno Bruto por un lapso de cuarenta años... Para un segundo grupo de países... con una deuda previsional entre 90 y 200 por ciento del Producto Interno Bruto, se deberían destinar recursos fiscales por montos entre 2.8 y 4.6 por ciento del PIB... en aquellos que fluctúan entre 20 y 50 por ciento del PIB... deberían asignar recursos fiscales anuales en montos equivalentes a cifras entre 0.7 y 1.4 por ciento del PIB"21.

La deuda previsional para 1997 ascendió a 64,489 millones de colones, lo que representó el

21. CEPAL, "El pacto fiscal", Chile, 1998. 
65 por ciento del Producto Interno Bruto de dicho año ${ }^{22}$. Siguiendo los cálculos de la CEPAL, este monto significó aproximadamente el 2 por ciento del Producto Interno Bruto durante cuarenta años y un 13 por ciento del presupuesto, si éste continúa representando el 15 por ciento sobre el Producto Interno Bruto. En otras palabras, se deberá destinar 13 por ciento del presupuesto anual durante los próximos 40 años para poder cubrir la deuda previsional. De modo que se presenta una carga o compromiso adicional a los gastos del Gobierno Central. En el anteproyecto de presupuesto para 1999, el rubro "Fondo de Amortización del Sistema de Pensiones" aparece - por primera vez- con una asignación de 90.7 millones de colones, que representa el 0.5 por ciento del monto total. Conforme el sistema vaya madurando, el cargo irá creciendo y demandará mayores proporciones del presupuesto.

Otro problema estriba en la inseguridad para el pago de pensiones a cotizantes que han optado por permanecer en el sistema del ISSS e INPEP. Se estima que esas instituciones agotarán sus reservas técnicas en los próximos 10 años, a consecuencia de la liquidación de los certificados de traspaso y del pago de pensiones con cargo al presupuesto.

\subsection{El presupuesto de 1999}

Por primera vez en la historia fiscal modema, en dos años consecutivos el presupuesto no ha sido aprobado con anticipación, sino al inicio de su ejecución. El correspondiente a 1998 se aprobó en enero de dicho año y el de 1999, no logró los votos suficientes para su aprobación antes del 31 de diciembre de 1998. Estas demoras son indicios de superación de la práctica convencional de aprobación del presupuesto. Tradicionalmente, el partido en el ejecutivo ha contado con suficientes votos para aprobar — sin mayor discusión y reformasel anteproyecto del Ministerio de Hacienda. La composición de las fracciones políticas en la asamblea electa para el período 1997-2000, ha posibilitado que la propuesta del Ejecutivo deba someterse a discusión y análisis en la Comisión de Hacienda y Especial del Presupuesto. Esto repre- senta un importante avance, en el sentido de un mayor consenso y participación de las diversas fuerzas políticas en la formulación de la política presupuestaria.

Asimismo, la organización de una unidad técnica de seguimiento a la ejecución presupuestaria es un paso importante, pero insuficiente. En tal sentido, podrían considerarse la elaboración de una política presupuestaria multianual, la aplicación de la Ley de la Corte de Cuentas y la práctica de auditorías de gestión. Por ahora, no se conoce de alguna auditoría de gestión, tomando en cuenta que dicha Ley data desde 1995, sino que se continúa con la tradicional auditoría financiera.

Sobre el contenido del anteproyecto de presupuesto de 1999, se vierten las apreciaciones siguientes:

* Se ha formulado con un fuerte déficit en su capacidad de financiamiento, que se refleja en la venta de títulos valores por un monto de $2,189.5$ millones de colones, que representan el 12.5 por ciento del presupuesto. Esta colocación ha sido cuestionada, dado que no ha sido previamente aprobada por la Asamblea, tal como lo exige la Constitución.

* Los problemas del vacío de financiamiento no provienen por el lado de lo que solicita el Órgano Judicial, los 1,098.3 millones de colones que solicita se exceden en 240.8 millones de colones al 6 por ciento de los ingresos corrientes calculados; en otras palabras, el elevado déficit no proviene de las exigencias del Órgano Judicial, ya que éste apenas representa el 11 por ciento de la insuficiencia de fondos.

La presión tributaria del 11.2 por ciento del Producto Interno Bruto para 1999 se encuentra sobrestimada. Conforme a cálculos propios, para 1999 la presión debe acercarse al 10.8 por ciento ${ }^{23}$. Es decir, 0.4 por ciento del Producto Interno Bruto por debajo de la estimación del presupuesto. $\mathrm{O}$ sea, aproximadamente 475.5 millones de colones vendrían a sumarse al déficit consignado en el anteproyecto.

22. Los cálculos de la deuda previsional para el caso de El Salvador fueron realizados por Carmelo Mesa-Lago y Fabio Durán, y están publicados en "Evaluación de la reforma de pensiones en El Salvador: antecedentes, objetivos y perspectivas”, Fundación Friedrich Ebert, El Salvador, 1998.

23. Los cálculos realizados a este respecto aparecen en el trabajo presentado por José Francisco Lazo, denominado "El Salvador, el gasto público en servicios sociales básicos. Iniciativa 20/20, equidad, eficiencia e impacto", que fuera realizado para el PNUD-UNICEF-MRREE, mimeografiado, El Salvador, 1998. 
* El proceso de privatización de activos del Estado significará una merma en las fuentes de financiamiento del presupuesto. Por la venta de activos, se calcula un ingreso de $\mathbf{2 5 . 0}$ millones de colones, que representan una disminución de 33.2 millones de colones respecto del presupuesto de 1998. De igual forma, en el ingreso por utilidades de las empresas, se prevé una reducción de Otro componente que está repercutiendo en el elevado déficit fiscal, se encuentra en la reducción de casi 100.0 millones de colones provenientes de la cuenta de recuperación de créditos.

* Otro aspecto por destacar se halla en los ingresos provenientes de Impuestos a Productos Especiales, que en su mayor parte provienen del consumo de productos dañinos a la salud humana, como aguardiente, licores, cerveza y tabaco. Este rubro disminuye nada menos que en 47.5 millones de colones. Llama la atención que en otros países, tanto desarrollados como subdesarrollados, la tendencia es a incrementar este tipo de impuestos $y$, en cambio, en el país se reducen.

* Ante las crecientes dificultades para su financiamiento, la inversión en activos fijos experimenta una reducción de 790.8 millones de colones. Esta sensible baja sugiere una actuación fiscal procíclica del Ministerio de Hacienda, lo cual puede contribuir a prolongar, de manera innecesaria, la actual coyuntura de bajo crecimiento económico.

* La distribución del presupuesto continúa presentando serias rigideces, la primera y más evidente es la importancia de las remuneraciones que ascienden a $7,174.8$ millones de colones ( 40.4 por ciento del total). El servicio de la deuda pública asciende a $2,706.3$ millones de colones ( 15.2 por ciento) y el financiamiento a las alcaldías a 781.7 millones de colones (4.4 por ciento). En conjunto, estos rubros captan el 60.0 por ciento del presupuesto.

* En cuanto a la distribución por áreas de gestión, el Desarrollo Social recibe la mayor parte, 35.6 por ciento. En orden de importancia, el rubro de Administración de Justicia y Seguridad Ciudadana absorben el 17.7 por ciento; en tercer lugar se encuentra la deuda Pública con 15.2 por ciento; el cuarto lugar le corresponde a la Conducción Administrativa con 13.3 por ciento, y en quinto lugar, el Apoyo al Desarrollo Económico con 10.9 por ciento. De acuerdo con esta composición, no se avizora la implementación de políticas sectoriales o focalizadas para atender el agro $u$ otros sec- tores que urgen de atención especializada. En todo caso, parece que el apoyo al Desarrollo Económico no es una prioridad para la actual administración pública.

\subsection{El impacto de Mitch en las finanzas públi- cas}

Los efectos destructivos del huracán Mitch en su paso por El Salvador son sensibles, aunque es de reconocer que en términos comparativos con Honduras y Nicaragua, la destrucción en nuestro país fue de menor grado.

Uno de los sectores más perjudicados, en términos del presupuesto, fue el de educación. Según datos proporcionados por el Ministerio de Educación, 818 escuelas públicas fueron afectadas de un total de 4905 , lo cual representa un 16.7 por ciento del total existente. Según cálculos iniciales, y por lo tanto subestimados, se requerirá por lo menos de 40.0 millones de colones para reparar los daños en infraestructura, mobiliario, material didáctico y equipo. Ello repercutirá en la asignación presupuestaria de dicho ministerio. Otros cálculos se acercan a los 70.0 millones de colones.

\section{Cuadro 12}

\section{Escuelas públicas afectadas por Mitch}

\begin{tabular}{lcrrrr}
\hline Departamento & Existentes & Dañadas & En alto riesgo & Sin acceso & $\begin{array}{c}\text { Total } \\
\text { afectadas }\end{array}$ \\
\hline Ahuachapán & 244 & 27 & 22 & 20 & 69 \\
Santa Ana & 429 & 25 & 44 & 24 & 93 \\
Sonsonate & 292 & 27 & 8 & 7 & 42 \\
Chalatenango & 360 & 4 & 2 & 0 & 6 \\
La Libertad & 440 & 34 & 18 & 45 & 97 \\
San Salvador & 667 & 0 & 27 & 0 & 27 \\
Cuscatlán & 197 & 0 & 0 & 0 & 0 \\
La Paz & 283 & 51 & 14 & 0 & 65 \\
Cabañas & 223 & 0 & 0 & 0 & 0 \\
San Vicente & 240 & 36 & 18 & 18 & 72 \\
Usulután & 424 & 45 & 35 & 68 & 148 \\
San Miguel & 458 & 43 & 32 & 21 & 96 \\
Morazán & 282 & 0 & 1 & 0 & 1 \\
La Unión & 366 & 34 & 8 & 60 & 102 \\
\hline Total & 4905 & 326 & 229 & 263 & 818 \\
\hline
\end{tabular}

Afectada: inundada o afectada parcialmente. En alto riesgo: tienen peligro de ser afectadas o inundadas. Sin acceso: imposible llegar a ellas.

Fuente: La Prensa Gráfica, 5 de noviembre de 1998; noticia que recoge información sobre el Ministerio de Educación. 
Otro ministerio que se ha visto afectado en su presupuesto es el de Obras Públicas. La reconstrucción de la infraestructura dañada, según cálculos conservadores, requerirá unos 150.0 millones de colones. Considerando los costos indirectos, como la disminución en la captación de impuestos por el efecto en la producción, los costos directos $\mathrm{e}$ indirectos del presupuesto superan los $400.0 \mathrm{mi}$ llones de colones. Estos costos vendrán a empeorar las dificultades de financiamiento mencionadas anteriormente.

\section{Gráfica 11 \\ Valor de las exportaciones \\ (miles de dólares)}

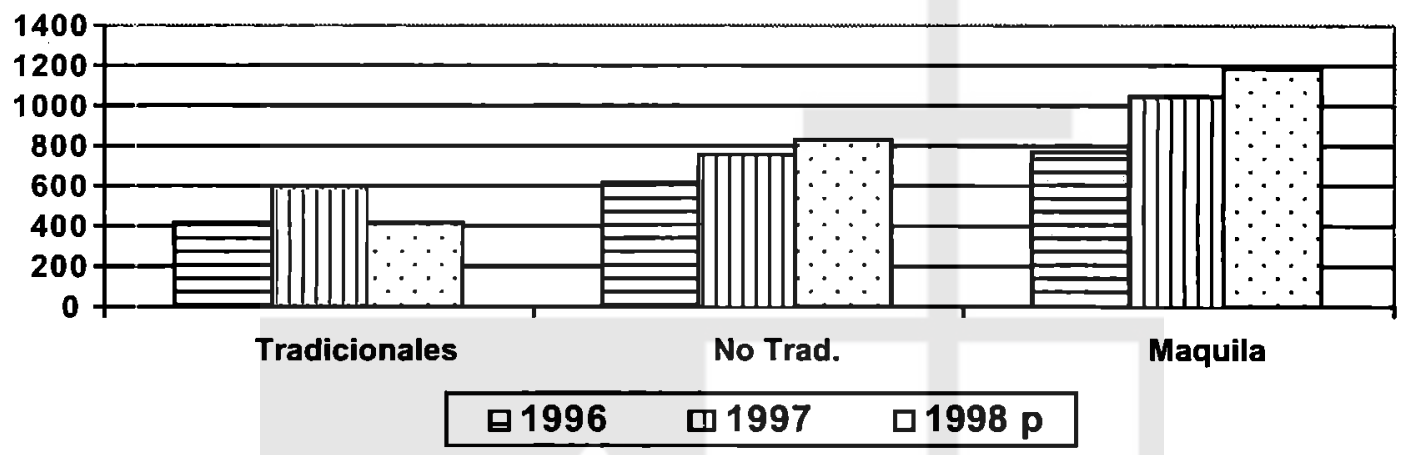

Fuente: Banco Central de Reserva.

\section{Evolución del sector externo}

\subsection{Exportaciones e importaciones}

El valor de las exportaciones de bienes en 1998 se incrementó en 1.2 por ciento con respecto al año anterior, mientras que el valor de las importaciones creció en 5.9 por ciento, lo cual incrementó el déficit comercial de 190 millones de dólares. Esto refleja que al finalizar el año, el crecimiento de las exportaciones estuvo muy por debajo de la proyección del 13.6 por ciento, establecida por el Banco Central de Reserva en el Programa Monetario de 1998. Comparando con 1997, las exportaciones y las importaciones crecieron un $35 \mathrm{y}$ 16 por ciento, respectivamente. La reducción en la dinámica de las exportaciones se asocia principalmente a un entorno internacional desfavorable para el café. A su vez, el volumen de exportaciones de café se reducirá este año, ya que la cosecha todavía refleja los efectos del fenómeno del niño ${ }^{24}$.
La reducción en los precios internacionales de café y del volumen exportado, implicó una baja en el valor de las exportaciones de café equivalente a 196 millones de dólares, monto muy cercano al incremento en el déficit de la balanza comercial. Sin embargo, en los otros rubros, las exportaciones continuaron mostrando una dinámica bastante positiva. El valor de las exportaciones -excluyendo café- se incrementó en 11.9 por ciento, el de las exportaciones no tradicionales en 10.7 por ciento y las exportaciones de maquila en 12.5 por ciento.

Con respecto a las exportaciones no tradicionales, al contrario de años anteriores -donde el crecimiento de las destinadas a Centroamérica era mayor que el de las exportaciones hacia el resto del mundo-, en 1998 las exportaciones no tradicionales hacia Centroamérica y el resto del mundo crecieron en 6.4 y 24.6 por ciento, respectivamente. Asimismo, las exportaciones de productos no

24. Pérez, Guillermo, "Café", Informe de Coyuntura, 14, Oficina de Análisis de Políticas Agropecuarias, Ministerio de Agricultura y Ganadería de El Salvador, octubre, 1998, pp. 23-45. 
tradicionales hacia el resto de Centroamérica mostraron una reducción drástica en su crecimiento con respecto al 26.6 por ciento del año anterior. Este movimiento aún no refleja el impacto de Mitch en las exportaciones hacia Centroamérica. Más bien, se espera que en 1999 las exportaciones hacia Honduras y Nicaragua se reduzcan o, por lo menos, que muestren una menor dinámica con respecto a 1998.

En cuanto a las exportaciones de maquila, más que fijarse en la evolución de las exportaciones brutas hay que concentrarse en las exportaciones netas, tal como se señalaba en el análisis de coyuntura económica del primer semestre de 1998 (Departamento de Economía, ECA, 599). Volvemos a repetir los cálculos para obtener las exportaciones netas de café y maquila hasta 1998.
La gráfica anterior muestra que hasta 1997, el café fue el principal rubro de exportación en el país, pero a partir de 1998 , la maquila se convirtió en el principal rubro de exportación. Ese cambio en el patrón de exportaciones del país responde a las políticas económicas que han tendido a favorecer más las no tradicionales, que las exportaciones tradicionales.

Retomando las importaciones, se mencionó que su crecimiento fue de 5.9 por ciento, comparado con el 16 por ciento que tuvo en 1997. Esta reducción en la dinámica de las importaciones se debe principalmente a la caída en el crecimiento de las importaciones de bienes de consumo (de 13.6 por ciento en 1997 a 1.2 por ciento en 1998) y de bienes intermedios (de 7.6 a 3.4 por ciento, respectivamente). Además, en relación con el año

Gráfica 12

Exportaciones netas al mes de noviembre (en millones de dólares)

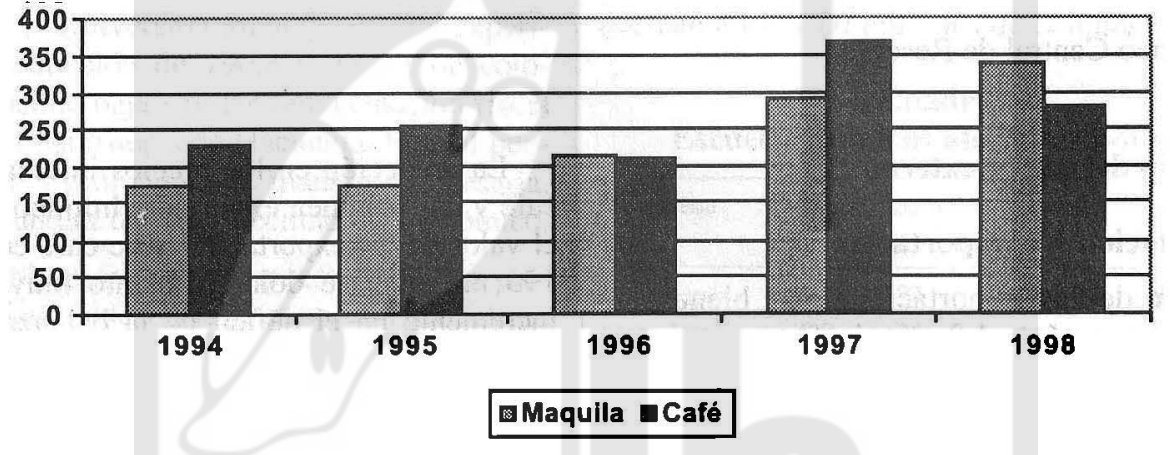

anterior, el crecimiento de las importaciones de bienes de capital fue menor -el 10.9 por ciento en 1998 comparado con el 19.9 por ciento en 1997. En cuanto al origen de las importaciones, sólo disponemos de información hasta noviembre de 1998. A finales de ese mes, las importaciones provenientes de Centroamérica crecieron 2.52 por ciento con respecto a 1997, y las provenientes del resto del mundo y de Maquila, crecieron 5.09 y 12.85 por ciento, respectivamente. En estas tres categorías, el crecimiento fue menor que el del año anterior. Cabe recordar también que, en 1998, las importaciones de bienes de consumo, intermedios, de capital y de maquila representaron el
$23.5,34.2,20.9$ y 21.5 por ciento, respectivamente. Es decir, el 76.6 por ciento del total de nuestras importaciones lo conforman bienes de producción. Tal composición demuestra lo esencial que son las importaciones para la manutención del aparato productivo y la generación de la actividad económica corriente.

Con respecto a la política comercial, hay que tomar en cuenta que durante 1998 se siguió implementando el Programa Nacional de Desgravación Arancelaria. Durante el año, el arancel se redujo en uno por ciento para los bienes intermedios y los bienes finales, mientras que los bienes 
de capital tuvieron un arancel de cero por ciento. Tales reducciones entraron en vigencia el primeró de enero y el primero de julio. Para 1999 se han programado también dos reducciones en los aranceles a bienes intermedios y bienes de consumo final, de uno por ciento cada una. La primera se encuentra vigente desde el primero de enero de 1999, y se espera que la segunda sea a partir del primero de julio.

\subsection{La balanza comercial de bienes}

Como se señaló anteriormente, el saldo de la balanza comercial fue negativo y correspondió a 1,513 millones de dólares, 190 millones de dólares más alto que en 1997. Este incremento en el déficit comercial se debe a que las exportaciones crecieron más despacio que las importaciones, lo cual se debió, en gran parte, a la reducción en los precios internacionales del café y la reducción del volumen de exportación de café. Una de las preguntas fundamentales es si la tendencia que se observaba hasta 1997, de una reducción relativa del déficit se mantuvo en 1998. No importa tanto el déficit en cifras absolutas sino su valor relativo, que puede ser con respecto a las exportaciones, o con respecto al Producto Interno Bruto. Sin embargo, para este último se requiere de información anual, ya que el Producto Interno Bruto se informa cada año y aún no se dispone de esa información. Por ello, se tomará en cuenta la relación exportaciones/importaciones, es decir, la proporción de las importaciones que se logró financiar con las exportaciones. Este último indicador se puede calcular con las cifras disponibles a corto plazo. Así, la Gráfica 13 muestra la relación exportaciones/importaciones.

Como se observa, en 1994 las exportaciones alcanzaron a financiar aproximadamente el 50 por ciento de las importaciones, pero esta relación aumentó hasta 1997 y luego disminuyó en 1998, al tenor de un entorno internacional desfavorable. Por tanto, se puede concluir que existe una tendencia hacia la reducción relativa del déficit comercial, ya que en 1998 , el 61.8 por ciento de las importaciones se lograron financiar con las exportaciones, lo que representa una tendencia positiva para la evolución del sector externo del país. No obstante esta tendencia a la mejoría de la situación relativa de la balanza comercial, la relación exportaciones/importaciones mostró una grave debilidad en el aparato productivo, dado que las exportaciones no fueron suficientes para el financiamiento de las importaciones.

Gráfica 13

Relación exportaciones/importaciones y su tendencia (en porcentaje)

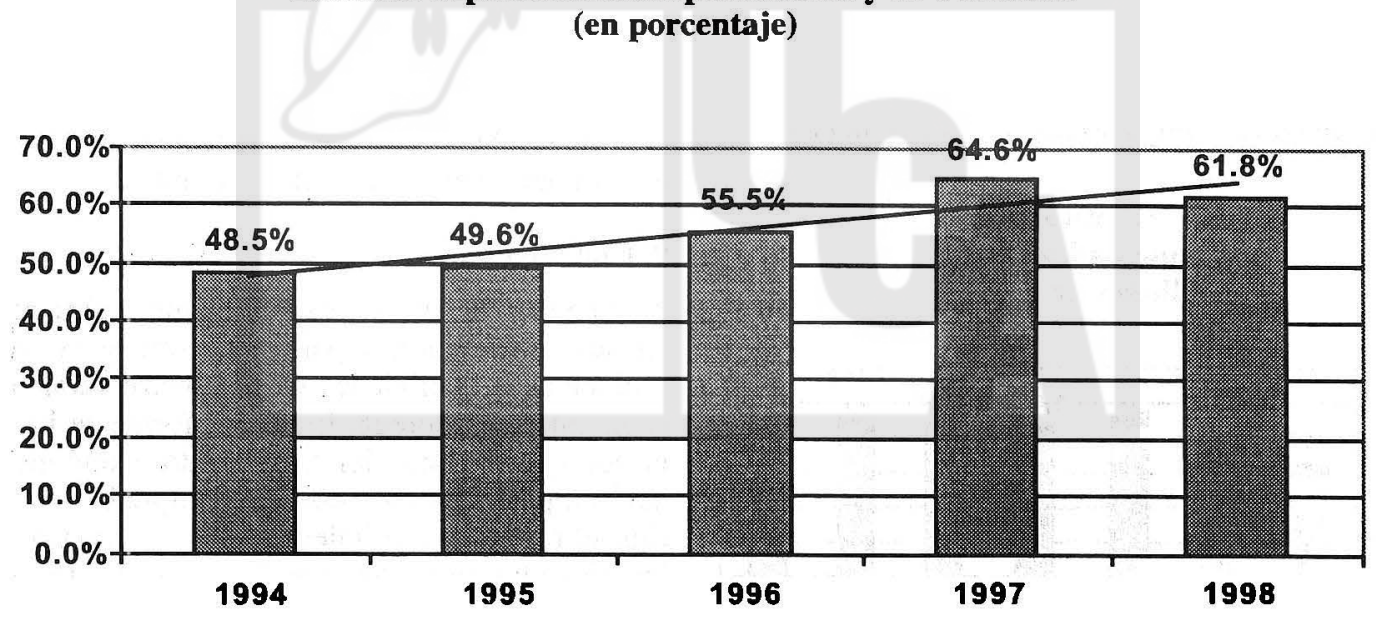




\subsection{La balanza de cuenta corriente}

La Balanza de Cuenta Corriente incluye las transferencias netas recibidas del exterior, las cuales se suman a la balanza comercial de bienes y servicios. La característica principal en El Salvador es el flujo de remesas familiares provenientes del exterior, lo que viene a saldar prácticamente el déficit que existe en la balanza comercial de bienes y servicios (ver Gráfica 14). Hasta diciembre de 1998, las remesas sumaron un total acumulado de aproximadamente 1,332 millones de dólares. Al final de año se informa un déficit en cuenta corriente de 83 millones de dólares, en contraste con el superávit de 96 millones de dólares del año anterior. En todo caso, cabe esperar un saldo final como porcentaje del Producto Interno Bruto, considerado relativamente bajo (todavía no se dispone de información). Lo que indica cierto grado de capacidad de solventar compromisos con el exterior. Sin embargo, esta capacidad se basa en remesas provenientes del exterior, y no en la capacidad del aparato productivo interno para generar ingresos.

\subsection{La balanza de capitales y el saldo de la ba- lanza de pagos}

La cuenta de capitales - al igual que el año anterior- muestra un saldo positivo, de $386 \mathrm{mi}$ llones de dólares en el presente año. ¿Cuál es la razón de esto? En primer lugar, dicho superávit indica una entrada neta de capitales del exterior. A su vez refleja una mayor inversión extranjera directa y la recepción de préstamos. Es decir, esa entrada neta de capitales significa que, tanto el sector privado como el sector público del país, están contrayendo mayores obligaciones con el extranjero.

\section{Gráfica 14 \\ Remesas familiares \\ (millones de colones)}

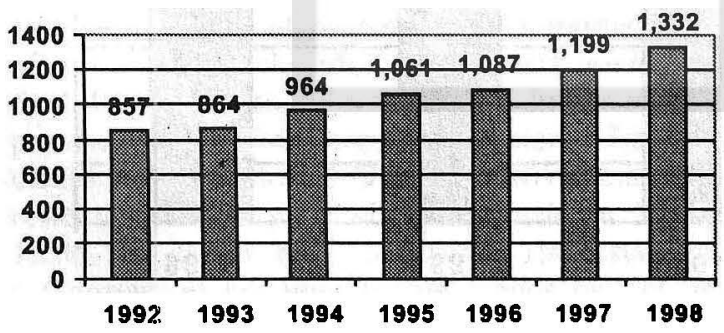

Fuente: Banco Central de Reserva.
Con respecto a la subcuenta de capital oficial, se obtuvo un saldo negativo. Probablemente el gobierno tuvo que pagar parte de su deuda externa y lo mismo vale para las operaciones del Banco Central de Reserva, que pudo haber invertido en el extranjero. El rubro Otros, que incluye Errores y Omisiones, Capital Privado y Bancos, obtuvo una cifra positiva de 479 millones de dólares, lo que indica una fuerte entrada de capital extranjero al país.

Estos movimientos se tradujeron en un saldo positivo de la balanza de pagos por 303 millones de dólares, equivalentes al incremento en las reservas internacionales entre diciembre de 1997 y diciembre de 1998. Por otra parte, el nivel de reservas internacionales considerado normal para un país como El Salvador, debe cubrir a aproximadamente 4 meses de importaciones. De este modo, se obtiene una cobertura de poco más de 6 meses de importaciones.

Por último, cabe mencionar un cambio sustancial en la balanza de pagos, específicamente en la balanza de capitales. Entre 1996 y 1997, la entrada de capitales se registró principalmente en el sector público, en los rubros de capital Oficial y Capital BCR. En cambio, en 1998, el sector público reportó saldos negativos, lo cual evidenció salida de capitales de este sector. En forma paralela, el agregado de Errores y Omisiones, Capital Privado y Banco Multisectorial de Inversiones, mostró un ingreso neto de capital extranjero. Tal resultado se vincularía a los avances del proceso de privatización, con la venta de las empresas públicas de telecomunicaciones y distribuidoras de energía eléctrica y con la privatización del sistema de pensiones. No obstante, parece que en los últimos meses hubo una salida fuerte de divisas que no ha logrado explicarse en su totalidad.

\section{Conclusiones}

El valor de estos análisis coyunturales reside en sus implicaciones para descubrir y constatar problemas o debilidades de tipo estructural de la economía salvadoreña. En este informe se ha destacado que el ritmo del crecimiento económico se debilita por el escaso poder de compra de los salarios, el raquítico crecimiento del consumo privado, las elevadas tasas de interés, el deterioro de la competitividad real y la delincuencia. En el fondo, este escenario conduce a plantear la interrogante de si el modelo económico ha entrado a una fase de agotamiento. 
Desde la perspectiva de los problemas estructurales de la economía salvadoreña sobresalen los aspectos siguientes:

1. El déficit crónico de la balanza comercial expresa, por una parte, el enorme rezago tecnológico de las empresas en El Salvador y, por ende, una débil capacidad competitiva. Por otra parte, evidencia una estructura productiva desintegrada, con severas restricciones para estimular su propia producción y demanda interna.

2. La economía nacional se acerca a una etapa de "crecimiento sin crecimiento", en el plano del desarrollo sostenible. Esta condición surge de la degradación del medio ambiente a un ritmo posiblemente mayor que la tasa de crecimiento del Producto Interno Bruto real. Por ejemplo, un estudio de FUSADES en 1997 estimó la degradación ambiental en 500 millones de dólares ${ }^{25}$.

3. El modelo económico vigente ha generado una trayectoria de crecimiento con subempleo y desigualdad. El escaso poder de compra de los salarios e ingresos de la mayoría de salvadoreños, determina una demanda interna deficiente. Por supuesto, esa débil capacidad adquisitiva se compensa, en parte, con remesas familiares. En tal sentido, nuestra economía se mantiene a flote gracias a esas divisas.

En definitiva, consideramos apremiante reconocer la dimensión estructural de estos problemas, como bases para articular un plan de desarrollo en forma concertada y participativa.

\section{Bibliografía}

Calvo, Guillermo A. y Végh, Carlos A., "From Currency Substitution to Dollarization and Beyond: Analytical and Policy Issues", en G. Calvo, Money, Exchange Rates, and Output, MIT Press, 1996.

Claassen, Emil-Maria y De La Cruz Martínez, Justino, "Dollarization and Its Impact on the Economy: Argentina, Bolivia, and Uruguay", Working Papers Series 168, Inter-American Development Bank, abril, 1994.

Enoch, Charles y Gulde, Anne-Marie, "Are Currency Boards a Cure for All Monetary Problems?", Finance \& Development, 4, Vol. 35, diciembre, 1998, Internet: http://www.imf.org.

Liviatan, Nissan, "Proceedings of a Conference on Currency Substitution and Currency Boards", World Bank Discussion Papers, Washington, D.C., 1992.

Melhado, Oscar Edgardo, El Salvador retos económicos de fin de siglo, San Salvador: UCA Editores, 1997, pp. 246 (ver capítulo III).

25. Panayotou, Faris, Restrepo, El desafío salvadoreño: de la paz al desarrollo sostenible, mayo, 1997, p. iv. 